This is the final peer-reviewed accepted manuscript of:

Francesco Baldi, Fredrik Ahlgren, Francesco Melino, Cecilia Gabrielii, Karin Andersson,

Optimal load allocation of complex ship power plants,

ENERGY CONVERSION AND MANAGEMENT, vol. 124, 2016

The final published version is available online at:

https://www.sciencedirect.com/science/article/pii/S0196890416305787

(C) 2016. This manuscript version is made available under the Creative Commons AttributionNonCommercial-NoDerivs (CC BY-NC-ND) 4.0 International License (http://creativecommons.org/licenses/by-nc-nd/4.0/) 


\title{
Optimal load allocation of complex ship power plants
}

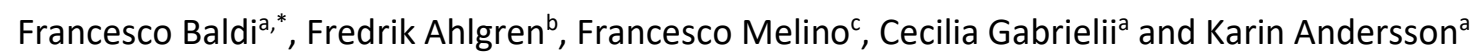

\author{
${ }^{a}$ Chalmers University of Technology, Department of Shipping and Marine Technology, Gothenburg, \\ Sweden \\ ${ }^{\mathrm{b}}$ Linnaeus University, Kalmar Maritime Academy, Kalmar, Sweden \\ ${ }^{\mathrm{c}}$ Alma Mater Studiorum - Universitá di Bologna, DIN, Bologna, Italy \\ * Corresponding author: Francesco.baldi@chalmers.se; +46 (0) 317722615
}

\section{Abstract}

In a world with increased pressure on reducing fuel consumption and carbon dioxide emissions, the cruise industry is growing in size and impact. In this context, further effort is required for improving the energy efficiency of cruise ship energy systems.

In this paper, we propose a generic method for modelling the power plant of an isolated system with mechanical, electric and thermal power demands and for the optimal load allocation of the different components that are able to fulfil the demand.

The optimisation problem is presented in the form of a mixed integer linear programming (MINLP) problem, where the number of engines and/or boilers running is represented by the integer variables, while their respective load is represented by the non-integer variables. The individual components are modelled using a combination of first-principle models and polynomial regressions, thus making the system nonlinear.

The proposed method is applied to the load-allocation problem of a cruise ship sailing in the Baltic Sea, and used to compare the existing power plant with a hybrid propulsion plant. The results show the benefits brought by using the proposing method, which allow estimating the performance of the hybrid system (for which the load allocation is a non-trivial problem) while also including the contribution of the heat demand. This allows showing that, based on a reference round voyage, up to $3 \%$ savings could be achieved by installing the proposed system, compared to the existing one, and that a NPV of 11 kUSD could be achieved already 5 years after the installation of the system.

\section{Introduction}

The shipping industry, despite its low contribution to global anthropogenic $\mathrm{CO}_{2}$ emissions today $(2.7 \%$ of the total as of 2012 [1]), will have to face increasingly stronger challenges in the future in relation to its contribution to global warming [1]. Most predictions suggest that shipping volumes (and, therefore, emissions) are expected to increase in the foreseeable future [1]. On the other hand, it has been shown that for achieving the $2^{\circ} \mathrm{C}$ climate goal shipping should reduce its $\mathrm{CO}_{2}$ emissions by more than $80 \%$ by 2050 compared to 2010 levels [2].

International regulations, such as the revised version of the International Convention for the Prevention of Pollution from Ships (MARPOL) [3], have started to put limits on ship emissions. Even further efforts are expected to be required if local regulations will be implemented. The European Union, for instance, is planning actions for achieving a 40-50\% reduction in $\mathrm{CO}_{2}$ emissions from ships 
visiting European harbours by 2050 [4], and in Sweden the fairway dues soon might be calculated against the clean shipping index which includes $\mathrm{CO}_{2}$ emissions.

\subsection{Energy efficiency in shipping}

Many new practices and technologies are being introduced for improving energy efficiency in the shipping sector. These measures are normally subdivided between operational and design.

Operational measures include efforts that do not require the installation of new equipment on board. Optimal voyage planning allows maximising the cargo transported while reducing the length of ballast legs [5], while adapting routes for avoiding conditions of bad weather can reduce the negative impact of high waves and strong winds on ship fuel consumption [6,7]; improving trim and draft setting, together with optimising the schedules and practices for hull and propeller polishing, lead to reduced ship resistance for a given speed [8-10]; slow steaming can also dramatically reduce the fuel bill: as the amount of cargo transported decreases linearly with the speed, while the power demand from the engines roughly depends on the cube of the speed, the advantage is obvious [11,12].

Retrofit and design measures, on the contrary, refer to physical technical solutions. This connects to the development of the performance of individual parts of the systems, such as the engine [13-16], the propeller [17,18], and the hull [19]. Additional energy sources can be used both for propulsion (e.g. sails and rotors $[20,21]$ ) and for auxiliary power generation (e.g. fuel cells [22]). Waste energy on board can be recovered in different ways, among other for heating, power [23-25], and cooling [26,27].

\subsection{Challenges of ship on board energy management}

Differently from a number of land-based systems, ships can operate in many different conditions and, hence, with large variations in power demand. This is even more challenging in the case of some specific ship types, such as cruise ships, where demand of energy in different forms (mechanical, electric, thermal) and of comparable size are observed. When in port, mechanical power demand for propulsion is virtually zero, while it can be predominant in sailing conditions, depending on the speed of the vessel. Demand for thermal energy can depend on the outer temperature of air and water, as well as on the number of passengers on board. Electric power demand can similarly vary as a function of environmental and operational conditions. These conditions require the ship power plant to be able to handle many combinations of energy demands with high efficiency.

Historically, ship energy systems have been built accordingly to a rather simple setup: one main engine connected to the propeller for propulsion, two (or more) auxiliary engines for auxiliary electric power generation, and a boiler for on board thermal power generation. According to this setup the three on board power demands (mechanical power for propulsion, electric power and thermal power for auxiliaries) are fulfilled by three systems individually [28]. In the latest years, however, the increasing requirements in terms of energy efficiency have fostered the introduction of new on board power plants with a higher degree of integration.

Different types of hybrid propulsion systems (i.e. systems where the systems for the generation of propulsive and electric power are interconnected) are gaining ground in the sector, as they allow for increased flexibility in fulfilling both propulsive and electric power demand. Such systems proved to allow fuel savings of 1-2\% [29]. These systems require however additional effort both in the design phase [30] and in the definition of the control strategy [31,32], as the increase in the number of connections between different parts of the system allows for the load to be fulfilled using a potentially high number of combinations of engines running at different loads. 
In most ships, the waste heat available from the engines is largely sufficient for fulfilling on board demand for thermal energy [33], and further uses for waste heat are today a common research topic [34-36]. On cruise ships, however, thermal energy demand is higher than on other ship types [37].

Systems with a higher degree of integration between the generation of mechanical, electric and thermal power are more complex as a consequence of the high number of relevant interactions among the different component of the systems [38]. This situation makes it more challenging to identify how to operate the system optimally from the perspective of its fuel consumption.

\subsection{Aim}

In this paper, we propose a method for optimising the load configuration of the energy converters of a ship power plant. More in general, the proposed load-optimisation method can be applied to energy systems with a time-dependent demand of mechanical, electric and thermal power with no connection to external energy networks.

The method proposed in this paper is applied to the energy system of a cruise ship. In particular, the method is to a proposed retrofit to the existing system where all engines are allowed to contribute to fulfil both the mechanical and the electric power demand. The application of the proposed method allows handling the increased complexity of the load-allocation problem and, therefore, evaluating the expected fuel savings derived by the system retrofit.

\section{Method}

The method presented in this study aims at being applicable to most of ship energy systems available today. The system configuration presented in Figure 1 is seen as sufficiently general with respect to the standard practice in today's shipbuilding industry. The system configuration therefore includes:

- Two propulsion lines: the most general system configuration on today's ships involves only one propulsion line, which can be seen as a particular case of the more general configuration of Figure 1

- Two main engine blocks, each composed by $\mathrm{n}_{\mathrm{ME}}$ engines

- Two auxiliary engine blocks, each composed by $n_{A E}$ engines, to accommodate for purely Dieselelectric systems equipped with engines of up to two different sizes.

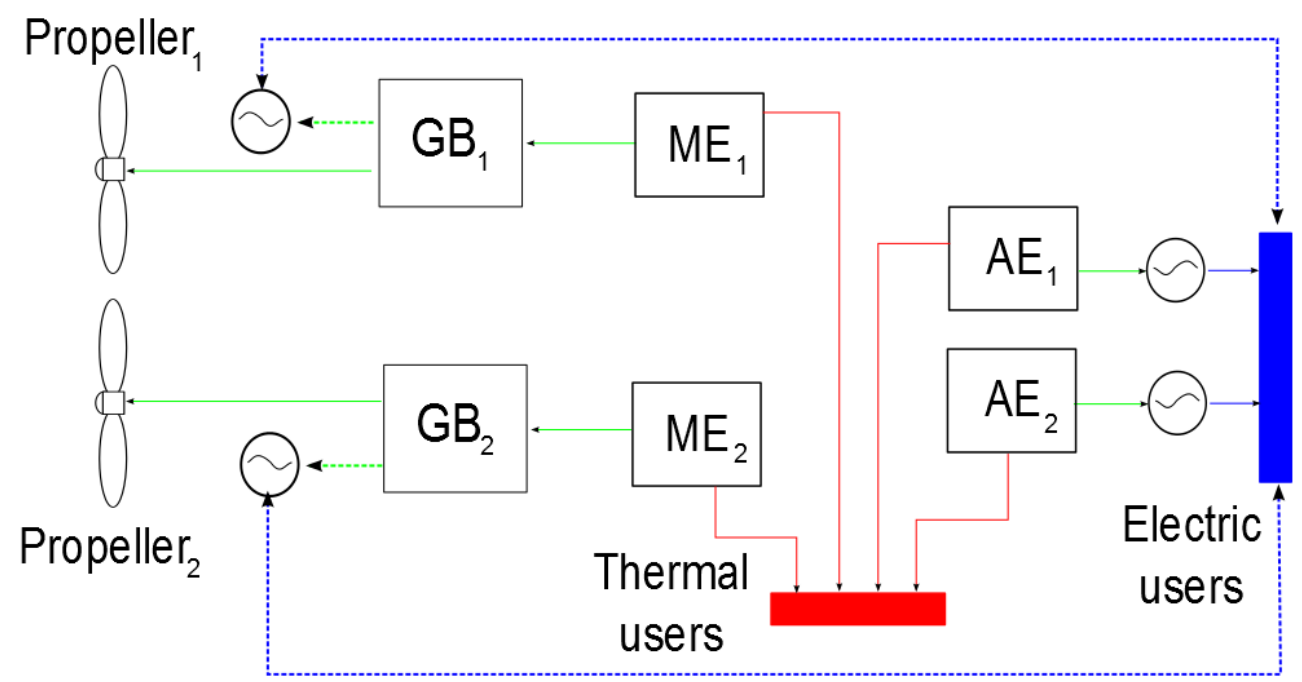

Figure 1: Schematic arrangement of a hybrid propulsion system 


\subsection{MINLP problem setting}

In all alternative systems, more than one possible configuration of engines running could be employed in order to fulfil the electric power demand. However, for each propulsion/electric power pair, there is one combination of main and auxiliary engines which fulfils the demand with the lowest fuel consumption. The selection of such combination requires an optimisation process, particularly in all cases where a hybrid propulsion system is available, since any engine can fulfil any demand.

The optimisation problem can be seen as a mixed integer nonlinear programming (MINLP) problem, where the integer variables are the number of engines running in each engine group and the continuous variables are the load of each engine group. The simplification of optimising the load of engine groups instead of individual engines is based on the assumption that, given that all the engines of the group have the same size and performance, it is most efficient to run all engines at the same load [39].

The optimisation problem can therefore be summarised as follows:

$$
\begin{array}{lll}
\text { Min } & & f(\bar{x}) \\
\text { s.t. } & & g_{\text {eq }}(\bar{x})=b_{\text {eq }} \\
& & g_{\text {neq }}(\bar{x})<b_{\text {neq }} \\
& & \text { For } i \text { in }(1,5) \\
& x_{i} \text { integer } \\
& \text { For } i \text { in }(6,18) & 0 \leq x_{i} \leq 1
\end{array}
$$

Where the subscripts $e q$ and neq refer to equality and non-equality constraints respectively. The objective function is defined as:

$$
f_{o b j}=\dot{m}_{M E 1}+\dot{m}_{M E 2}+\dot{m}_{A E 1}+\dot{m}_{A E 2}+\dot{m}_{A B}
$$

Where each of the mass flows is calculated according to:

$$
\dot{m}_{i}=\frac{\lambda_{i} M C R_{i} n_{i, o n}}{\eta_{i}\left(\lambda_{i}\right) L H V_{\text {fuel }}}
$$

Where the LHV of the fuel is that of marine heavy fuels, assumed equal to $40.7 \mathrm{MJ} / \mathrm{kg}$ [40], while $\lambda_{i}$ and $\eta_{i}$ represent the load and the efficiency of the $i$-th group of engine/boilers, respectively. Each of the mass flows in Equation (6) can therefore be defined as a function of the load of the component block (elements 6-18 in $\bar{x}$ ), and on the number of elements in the component block that are running (elements $1-5$ in $\bar{x}$ ).

The first five elements of $\bar{x}$ represent the number of engines/boilers that are running in each of the groups (e.g. $n_{M E 1, o n}$ for the first group of main engines) while the elements from 6 to 18 represent the load of each of the engine/boiler groups connected to a specific demand. For instance:

$$
x_{6}=\lambda_{M E 1 \rightarrow \text { prop } 1}=\frac{P_{M E 1 \rightarrow \text { prop } 1}}{M C R_{M E 1}}
$$

Represents the share of the mechanical power generated by the $1^{\text {st }}$ group of main engines which is used by the $1^{\text {st }}$ propeller. Therefore, for each group of engines the following three elements in the $\bar{x}$ vector are represented:

$$
\lambda_{i \rightarrow \text { prop } 1} \quad \lambda_{i \rightarrow \text { prop } 2} \quad \lambda_{i \rightarrow e l}
$$

Finally, element 18 represent the auxiliary boiler(s) load:

$$
x_{18}=\lambda_{A B \rightarrow t h}=\frac{\dot{Q}_{A B}}{\dot{Q}_{a b, \max }}
$$

The nonlinear equality conditions represent the requirement that the system is able to fulfil the totality of the mechanical power demand from the two propeller and the electric demand: 


$$
\left\{\begin{aligned}
P_{\text {prop } 1} & =\sum_{i} P_{i \rightarrow \text { prop } 1} \eta_{i \rightarrow \text { prop } 1} \\
P_{\text {prop } 2} & =\sum_{i} P_{i \rightarrow \text { prop } 2} \eta_{i \rightarrow \text { prop } 2} \\
P_{e l} & =\sum_{i} P_{i \rightarrow e l} \eta_{i \rightarrow e l}
\end{aligned}\right.
$$

The nonlinear inequality conditions represent the requirement that each of the engines/boilers in the systems is not loaded above its maximum load and below its minimum load.

$$
\left\{\begin{array}{l}
P_{M E 1, \min } n_{M E 1, \text { on }} \leq P_{M E 1 \rightarrow \text { prop } 1}+P_{M E 1 \rightarrow \text { prop } 2}+P_{M E 1 \rightarrow e l} \leq P_{M E 1, \max } n_{M E 1, \text { on }} \\
P_{M E 2, \min } n_{M E 2, \text { on }} \leq P_{M E 2 \rightarrow \text { prop } 1}+P_{M E 2 \rightarrow \text { prop } 2}+P_{M E 2 \rightarrow e l} \leq P_{M E 2, \max } n_{M E 2, \text { on }} \\
P_{A E 1, \min } n_{A E 1, \text { on }} \leq P_{A E 1 \rightarrow \text { prop } 1}+P_{A E 1 \rightarrow \text { prop } 2}+P_{A E 1 \rightarrow e l} \leq P_{A E 1, \max } n_{A E 1, \text { on }} \\
P_{A E 2, \min } n_{A E 2, \text { on }} \leq P_{A E 2 \rightarrow \text { prop } 1}+P_{A E 2 \rightarrow \text { prop } 2}+P_{A E 2 \rightarrow e l} \leq P_{A E 2, \text { max }} n_{A E 2, \text { on }}
\end{array}\right.
$$

The last of the inequality conditions requires the sum of the available waste heat from the engines and the heat generated by the boilers to be larger than the total heat demand

$$
\dot{Q}_{W H, M E 1}+\dot{Q}_{W H, M E 2}+\dot{Q}_{W H, A E 1}+\dot{Q}_{W H, A E 2}+\dot{Q}_{A B} \geq \dot{Q}_{t h}
$$

Where the waste heat from each engine is calculated as explained in Section 2.2.

MINLP problems can be solved in different ways depending on the structure of the different parts of the optimisation problem [41]. In this case, the optimisation problem was solved using a sequential quadratic programming (SQP) algorithm (built-in Matlab ${ }^{\circledR}$ NLP solver fmincon in SQP mode) for the solution of the NLP programming. A branch-and-bound method was implemented by the authors for handling integer variables [42].

\subsection{Diesel engines}

The Diesel engines are modelled based on the information provided by engine manufacturers in dedicated documentation, such as what available from [43] and [44] for the engines installed on the ship that is used as test case in this paper (see Section 3.1 for a more detailed description of the test case).

The efficiency of the Diesel engines, both main and auxiliary engines, are calculated using $2^{\text {nd }}$ degree polynomial regressions based on data from the engine manufacturers. A penalty term $f_{\text {corr, }, s o}$ is used to account for the engines not operating in ISO conditions in terms of ambient temperature, ambient pressure, cooling water temperature and fuel LHV [45]. An additional penalty term of 1.05 is arbitrarily assigned in order to account conservatively for the tolerance allowed in the calculation of the efficiency of the engines in ISO conditions [45]. Engine efficiency is therefore calculated according to Equation (19):

Where $\lambda$ represents the engine's load.

$$
\eta_{\text {eng }}=1.05 f_{\text {corr }, I S O} P_{2}(\lambda)
$$

Waste heat flows from both the MEs and the AEs needs to be modelled for on board WHR. However, as previously observed by Marty [46], the values provided by the engine manufacturers often do not respect the conservation of energy on the engines. The following method is therefore employed to update the values provided by the manufacturers in order to obtain consistent output energy flows from the engines. 
Starting from the engine load, the air flow through the cylinders can be calculated according to Eq. (20):

$$
\dot{m}_{\text {air }, c y l}=\eta_{v o l} \frac{p_{c a}}{R_{\text {air }} T_{c a}} V_{c y l, m a x} n_{\text {eng }} N_{c y l}
$$

Where $\eta_{v o l}$ represents the volumetric efficiency of the engine, and is calculated as suggested by Hiereth and Prenninger [47]; $p_{c a}$ represents the charge air pressure, and is calculated as a function of the engine load based on polynomial regressions of measured data obtained from on board alarm systems; $T_{\text {ca }}$ represents the charge air temperature, which is generally regulated by the cooling systems control to a value of approximately $50-60^{\circ} \mathrm{C} ; \mathrm{V}_{\mathrm{cy}, \max }$ represents the cylinder maximum volume, $\mathrm{n}_{\text {eng }}$ the engine speed and $\mathrm{N}_{\mathrm{cyl}}$ the number of cylinders.

The equations related to the energy balance of the turbine and of the mixer of flows 3,5,6, as well as the mass balance in splitter and mixer must be solved simultaneously:

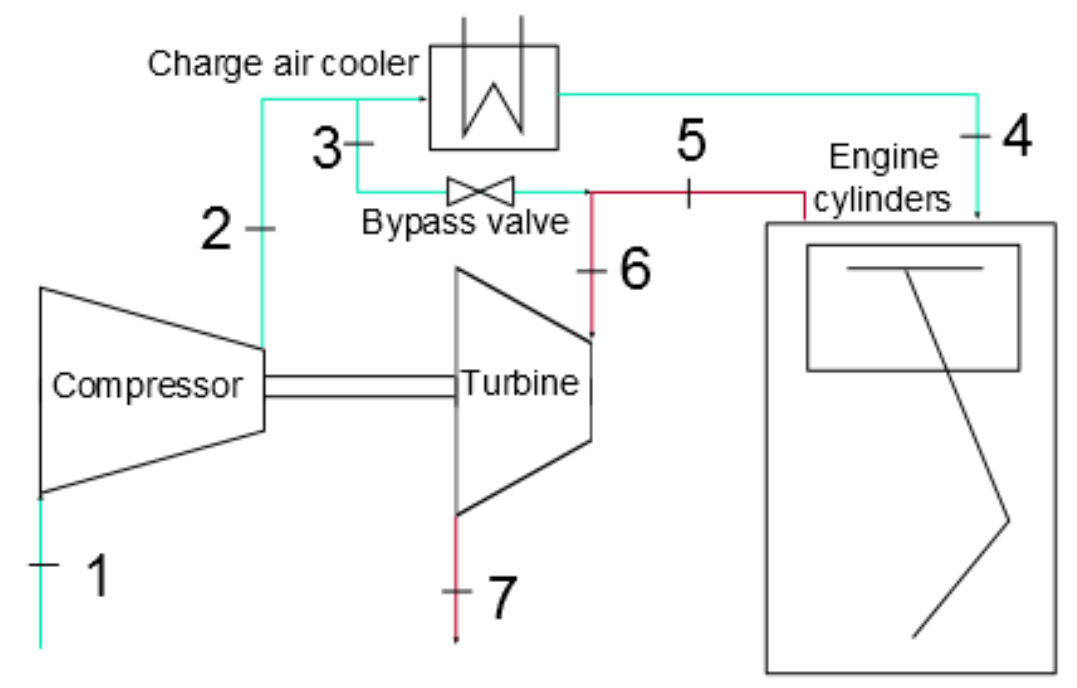

Figure 2: Schematic representation of the main engines turbocharging system, with bypass

$$
\left\{\begin{array}{ccc}
\dot{m}_{1} c_{p, a i r}\left(T_{2}-T_{1}\right) & = & \eta_{m e c h, T c} \dot{m}_{6} c_{p, e g}\left(T_{6}-T_{7}\right) \\
\dot{m}_{6} c_{p, e g}\left(T_{6}-T_{0}\right) & = & \dot{m}_{5} c_{p, e g}\left(T_{5}-T_{0}\right)+\dot{m}_{3} c_{p, \text { air }}\left(T_{3}-T_{0}\right) \\
\dot{m}_{1} & = & \dot{m}_{3}+\dot{m}_{4} \\
\dot{m}_{6} & = & \dot{m}_{5}+\dot{m}_{3}
\end{array}\right.
$$

Where $\eta_{\text {mech,TC }}$ represents the mechanical efficiency of the turbocharger, assumed equal to 0.98 , and $c_{p \text {,air }}$ and $c_{p, e g}$ the specific heat of air and exhaust gas, assumed constant with temperature and equal to 1.02 and $1.08 \mathrm{~kJ} / \mathrm{kg}$ respectively. In the formulation of Equations (21) and (22) it is assumed that the mass flow of the exhaust gas leaving the cylinders is sufficiently larger than the bypass flow, thus allowing to assume that the specific heat of the mixed flow is equal to that of the pure exhaust gas flow from the cylinders.

The system of equations (21)-(24), together with equation (20), requires four of the variables to be determined in advance in order to be solved. The definition of these four variables depends on the availability of measured data in each individual case. The assumptions for the specific test case presented in this paper will be presented further in Section 3.

The aforementioned procedure allows calculating all physical flows in the engine, and therefore the energy leaving in the form of exhaust gas and available for recovery $\left(\dot{Q}_{e g, M E}\right)$ :

$$
\dot{Q}_{e g, M E}=\dot{m}_{7} c_{p, e g}\left(T_{7}-433\right)
$$


where the lower limit of $433 \mathrm{~K}$ is assumed based on the need to avoid sulphuric acid condensation in the exhaust gas [48].

Marine engines are generally cooled using both a high temperature (HT) and a low temperature (LT) cooling system. The temperature of the $\mathrm{HT}$ cooling systems ranges between 70 and $90^{\circ} \mathrm{C}$, while the temperature in the $\mathrm{LT}$ cooling systems generally ranges between 30 and $50^{\circ} \mathrm{C}$. For this reason it is assumed that only the heat transferred to the HT cooling systems is available for recovery.

The calculation of the thermal power available in the HT cooling systems is based on the energy balance over the engine:

$$
\dot{Q}_{H T}=f(\lambda)\left[\dot{m}_{f u e l} L H V_{f u e l}+\dot{m}_{1} c_{p, a i r}\left(T_{1}-T_{0}\right)-P_{\text {mech }}-\dot{m}_{7} c_{p, e g}\left(T_{7}-T_{0}\right)\right]
$$

where $f(\lambda)$ represents the fraction of the residual heat that is transferred to the HT cooling system, and is calculated as a polynomial regression of data available from the engine technical documentation.

\subsection{Oil-fired Boilers}

Marine oil-fired boilers are generally dimensioned for providing high performance even at very low loads. For these types of systems it is therefore assumed that the part-load efficiency can be modelled using a linear step-wise interpolation (see Figure 3 ) as based on the efficiency curves for marine boilers presented by Cohen [49]:

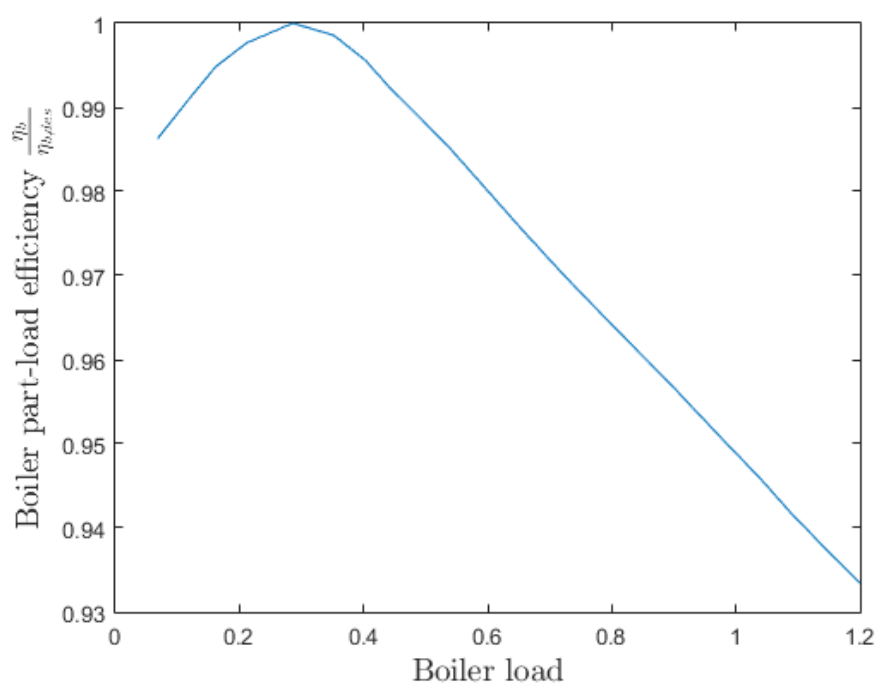

Figure 3: Boiler efficiency, relative to design, versus load

The design efficiency can be assumed to $90 \%$ in absence of more specific information.

\subsection{Other components}

All other components on board are modelled according to the following approximation:

$$
\eta=\eta_{\text {des }} f_{\text {corr }}(\lambda)
$$

Where $\eta_{\text {des }}, \lambda$ and $f_{\text {corr }}$ represent the efficiency at the design point, the load of the component, and the correction factor that represents the off-design behaviour.

$f_{\text {corr }}$ is calculated using a $2^{\text {nd }}$ degree polynomial approximation both for mechanical components (gearboxes) and for electrical components (generators, motors, and frequency converters) based on [50]. The evolution of the efficiencies for electrical machines and the gearbox with load is provided in Figure 4 . The efficiency of the frequency converter, the switchboard and the shaft are assumed to be 
constant with load. The design efficiencies of all the components in design conditions are presented in Table 1

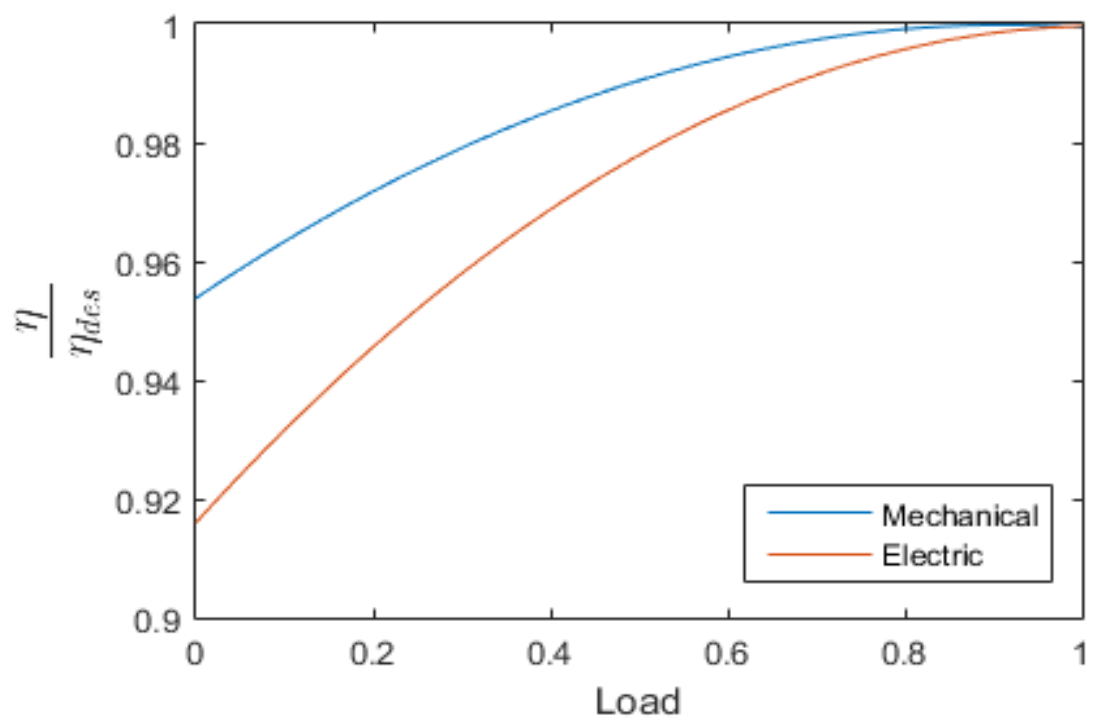

Figure 4: Off-design efficiency correlations for mechanical and electric machines

Table 1: Design efficiencies for mechanical end electric machines

\begin{tabular}{lll}
\hline Component & $\eta_{\text {des }}$ & \\
\hline Gearbox & 0.98 & {$[51]$} \\
Generator & 0.97 & {$[52]$} \\
Motor & 0.96 & {$[52]$} \\
Frequency converter & 0.98 & {$[53]$} \\
Switchboard & 0.99 & {$[53]$} \\
Shaft & 0.99 & {$[51]$} \\
\hline
\end{tabular}

\section{Test case}

\subsection{Description of the case study}

The case study ship is a cruise ship which operates daily tours in the Baltic Sea between Stockholm on Swedish mainland and Mariehamn on the Åland islands. The ship was built in 2004 and is $176.9 \mathrm{~m}$ long and $28.6 \mathrm{~m}$ wide. It can accommodate up to 1800 passengers and is equipped with restaurants, night clubs and bars, as well as saunas and pools. Typical ship operations, although they can vary slightly between different days, are represented in Figure 1. The ship leaves at around 18 from Stockholm, until it reaches the open sea, where it stops for the night before reaching Mariehamn early in the morning. The ship then leaves Mariehamn at around 9 AM and arrives back to Stockholm at around 4 PM (see Figure 5). 


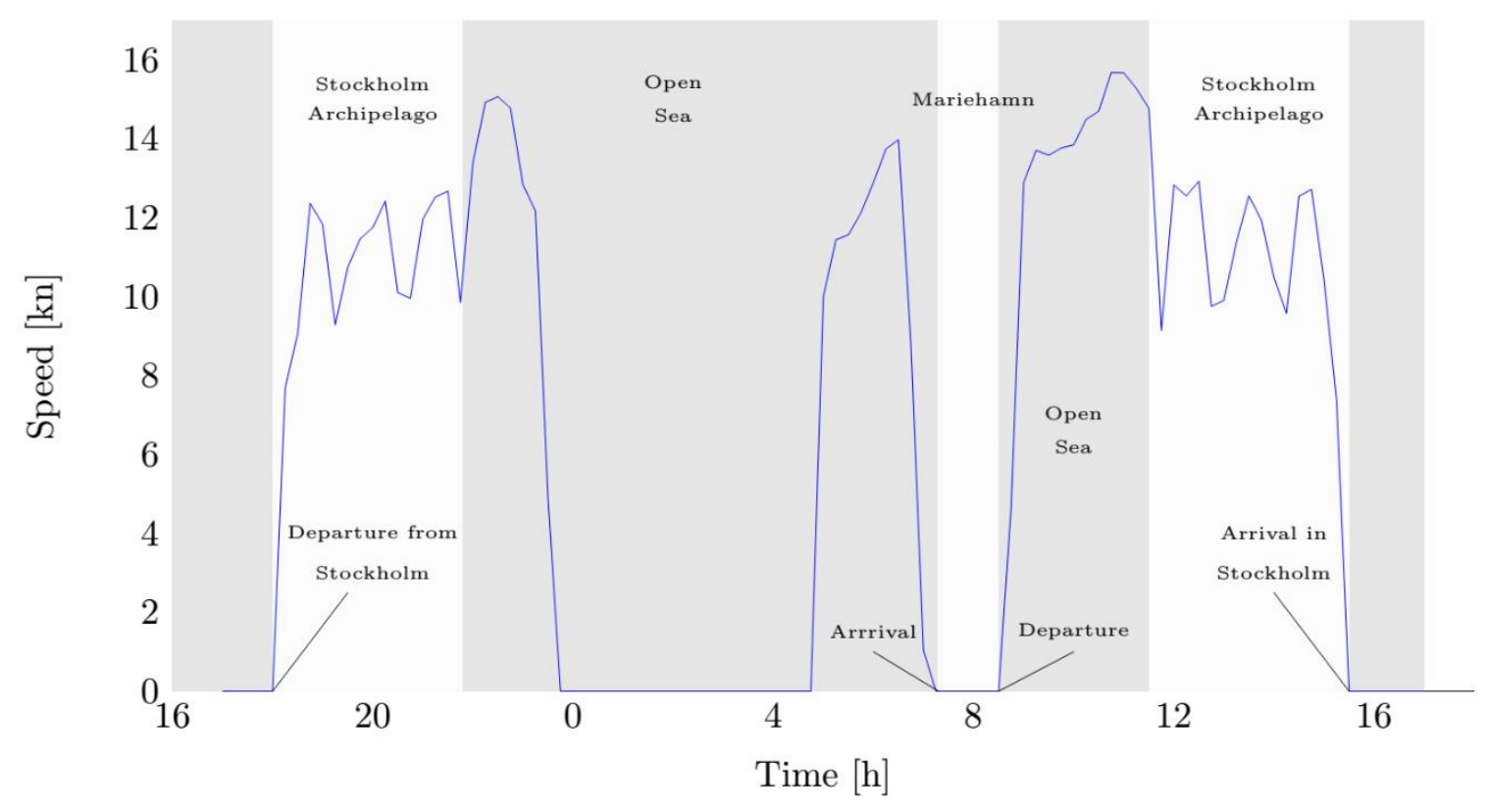

Figure 5: Typical operational profile (ship speed) for the selected ship.

The ship energy system is summarized in Figure 6. The propulsion system is composed of two propulsion lines composed of two main engines, a gearbox, and a propeller each.

The main engines (ME) are four Wärtsilä $6 \mathrm{~L} 46$ 4-stroke Diesel engines rated $5850 \mathrm{~kW}$ each [43]; The ship is also equipped with four Wärtsilä $6 L 32$ auxiliary engines (AE) for electricity production, rated $2760 \mathrm{~kW}$ each [44]. All AEs and one ME for each propulsion line are also equipped with heat recovery steam generators (HRSG); in addition, two auxiliary boilers (AB) are installed on board; finally, the hightemperature (HT) cooling systems of all engines are connected to a heat recovery system which allows to use such heat for accommodation heating. All engines are equipped with selective catalytic reactors (SCR) for $\mathrm{NO}_{\mathrm{x}}$ emissions abatement.

Propulsion power is provided by the MEs connected to the two propulsion lines, and is needed whenever the ship is sailing. Auxiliary power is needed on board for a number of alternative functions, from pumps in the engine room to lights, restaurants, ventilation and entertainment for the passengers. Auxiliary heat demand is mostly fulfilled by the HRSGs and by the heat recovery from the $\mathrm{HT}$ cooling; $\mathrm{ABs}$ are mainly used when in port, or during winter. The heat is needed for passengers and crew accommodation, as well as for the heating of the highly viscous heavy fuel oil used for engines and boilers.

Table 2: Summary of energy sources on board of the case study vessel

\begin{tabular}{|c|c|c|}
\hline Component block & Number & Design power [kW] \\
\hline Main engines -1 & 2 & 5850 \\
\hline Main engines -2 & 2 & 5850 \\
\hline Auxiliary engines & 4 & 2760 \\
\hline Auxiliary boilers & 2 & 4500 \\
\hline
\end{tabular}

\begin{tabular}{lrr}
\hline \multicolumn{1}{c}{ Engine property } & \multicolumn{1}{c}{$\mathrm{ME}$} & \multicolumn{1}{c}{$\mathrm{AE}$} \\
\hline Cylinder bore [mm] & 460 & 320 \\
Stroke $[\mathrm{mm}]$ & 580 & 400 \\
Piston displacement [l/cyl] & 96.4 & 32.2
\end{tabular}




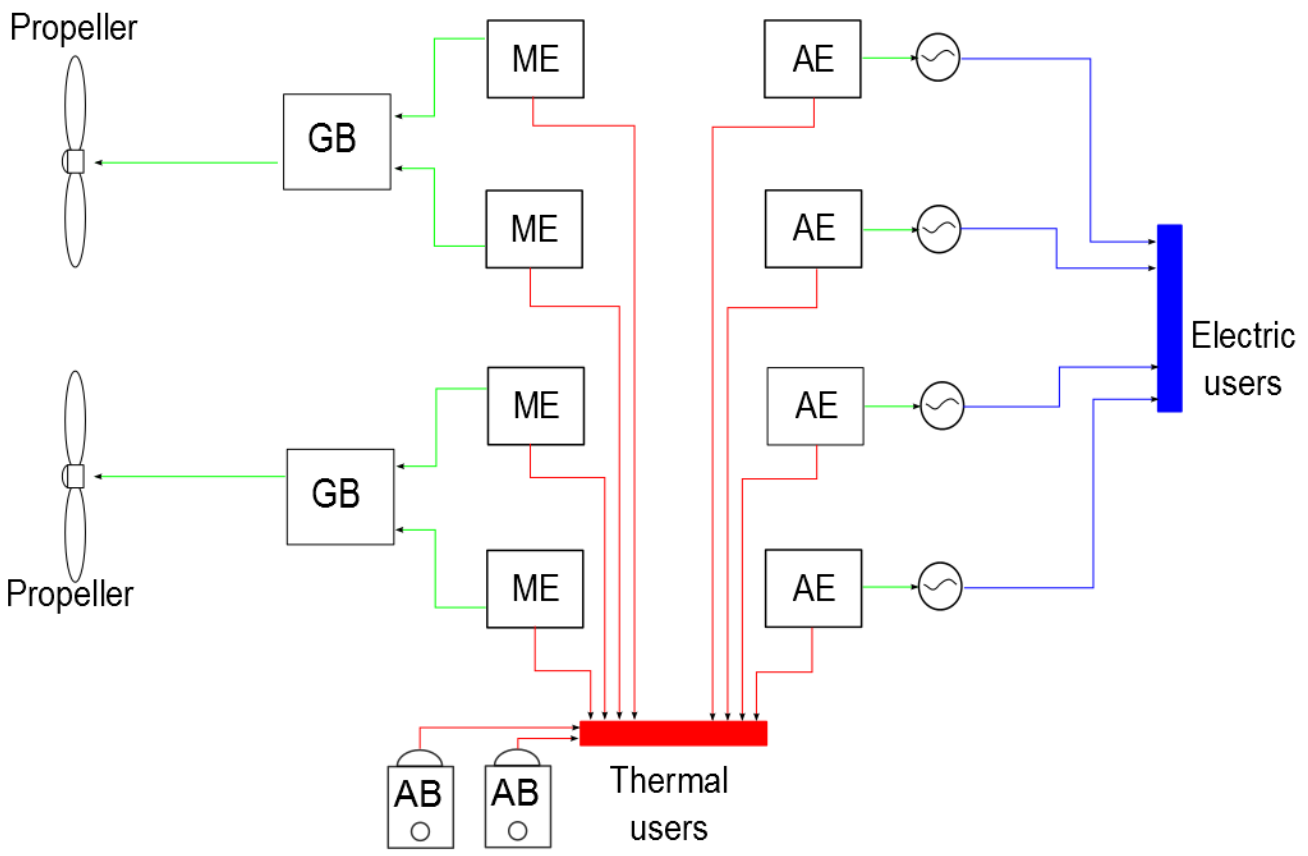

Figure 6: Schematic representation of the case study's energy system

According to the methodology presented in Section 2.2, the efficiency and the waste heat flows of the main and auxiliary engines vary with engine load as represented in Figure 7 and Figure 8.

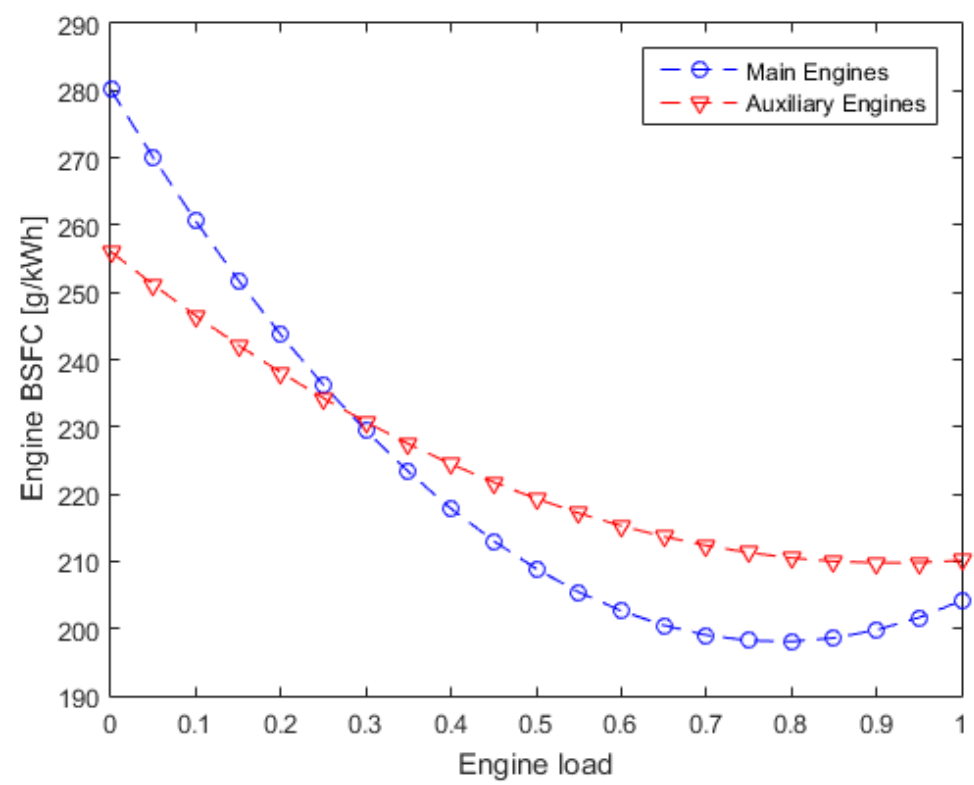

Figure 7: Main and auxiliary engines BSFC versus engine load, from regressions 


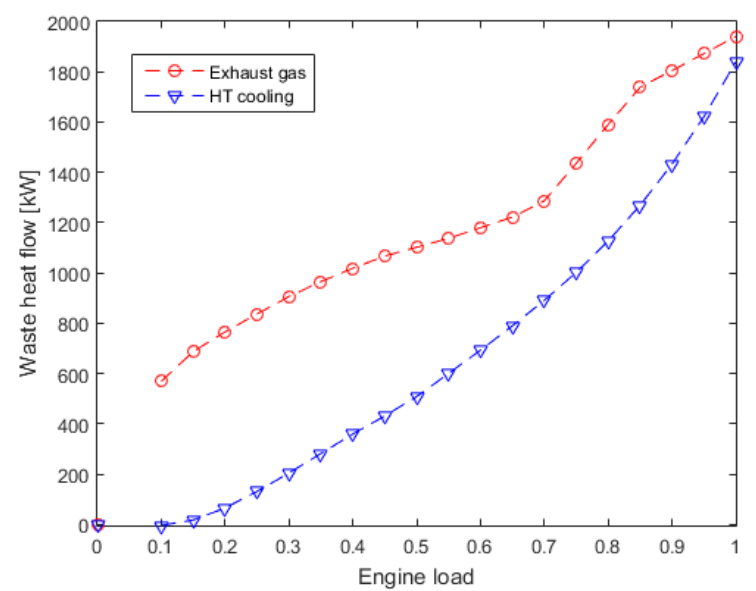

(a) Main Engines

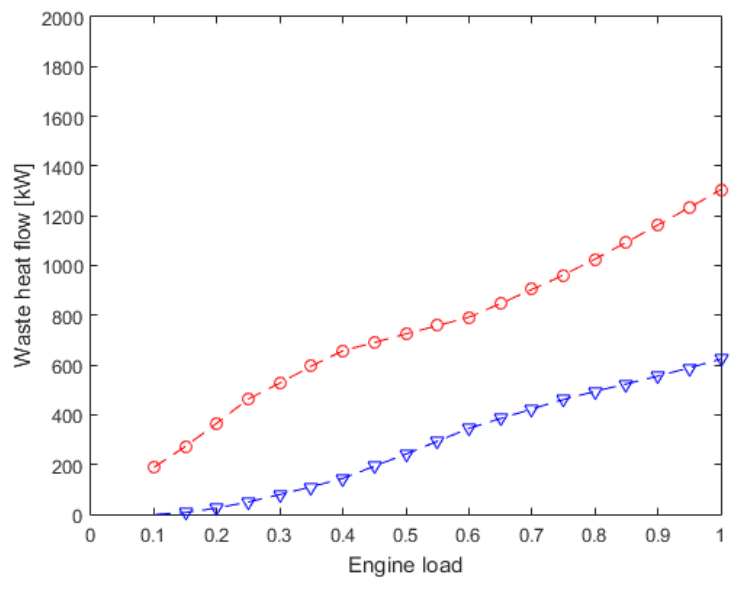

(b) Auxiliary engines

Figure 8: Main and auxiliary engines waste heat versus engine load

\subsection{On board power demand}

For testing the application of the aforementioned method to the case study ship, the evolution of on board demand for propulsion, auxiliary power and auxiliary heat needs to be provided. This was determined based on data collected from the on board monitoring system.

- Propulsive power demand was determined based on measurements of MEs fuel rack position and speed. The fuel rack position is measured by a dedicated sensor, while the engine speed is measured optically on the shaft. The combination of these two variables allows to estimate fuel mass flow rate, which in turn, using technical documentation related to engines performance, was used to determine the instantaneous propeller power demand. Although there is no documentation available for the uncertainty of the individual measurements, by assuming the uncertainty on the engine speed, engine fuel rack position and engine efficiency an uncertainty of $1 \%$ [54], 3\% and $5 \%$ [45] respectively, the uncertainty of the propulsive power measurement can be estimated to $6 \%$.

- The electric power generated by the auxiliary generators was directly measured on board, with a measurement uncertainty below $1 \%$.

- Thermal power demand was determined based on the estimated thermal power recuperated from the HRSGs and on measured fuel consumption from the ABs. The method employed in this phase could only lead to an estimation of the daily energy demand. For this reason, we employed the assumption that the on board thermal power demand follows a similar trend as what represented in Figure 10, which refers to the thermal power demand of a hotel. Given the absence of direct measurements of on board heat demand it is not possible to provide a precise estimation of the measurement uncertainty, which can however be estimated to lie in the range of $10 \%$.

A detailed description of the methodology employed for the determination of the demand of propulsive, electric and thermal power is proposed in [37]. A representation of propulsive and electric power distribution is provided in Figure 9. It can be seen that, from the analysis of the data collected from the ship on board systems, it resulted that the ship rarely sails at full speed, and most of the time it only needs only a small fraction of its design power. 


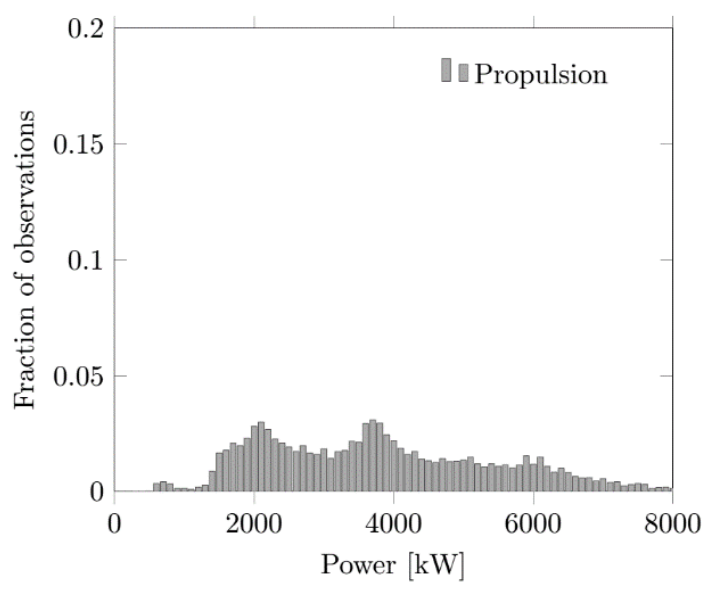

(a): Propulsive power

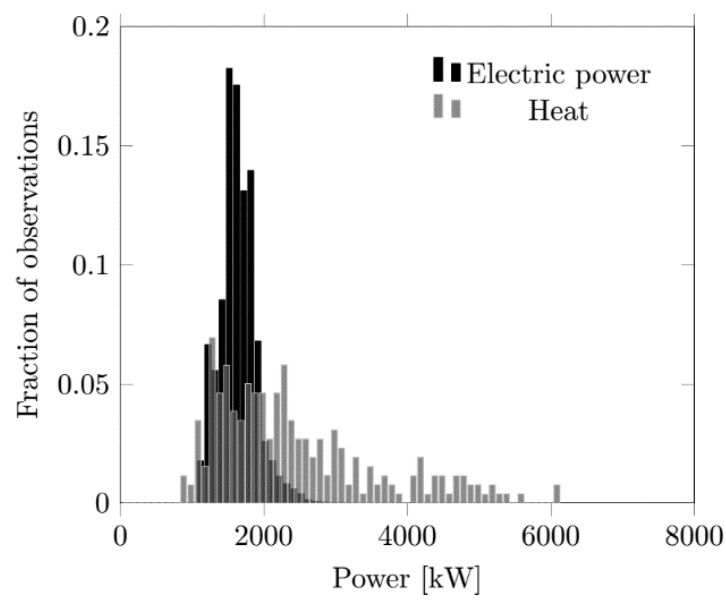

(b) Auxiliary power

Figure 9: Power demand distribution

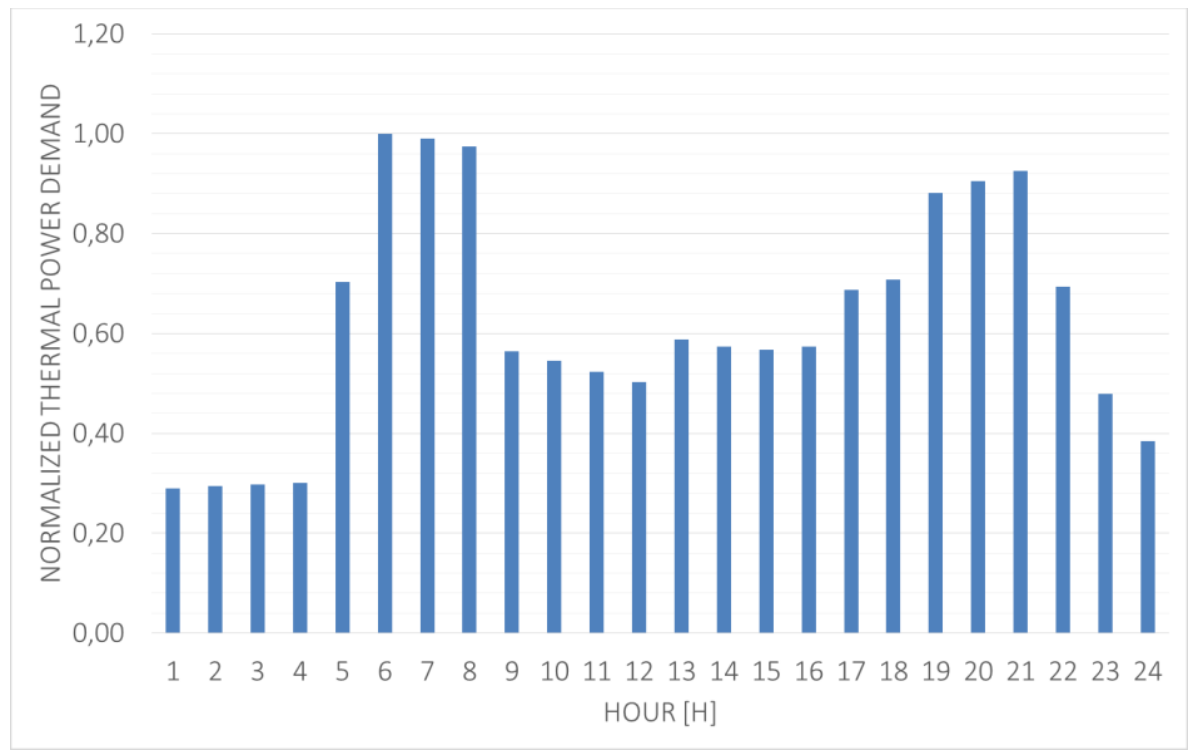

Figure 10: Hourly distribution for on board thermal energy demand

\subsection{Shaft generator/motor installation}

Given that both main and auxiliary engines on board of the selected vessel are often operated at low load, and therefore at sub-optimal conditions, the possibility of improving the efficiency of the system through the installation of shaft generators/motors connected to the main engines was explored. This would allow a larger freedom in the utilisation of the power generation system, as any engine could provide power to any of the demands. This comes however at the cost of increased conversion losses in the electrical components. The hybrid propulsion system proposed for retrofit on the selected vessel is shown in Figure 11: 


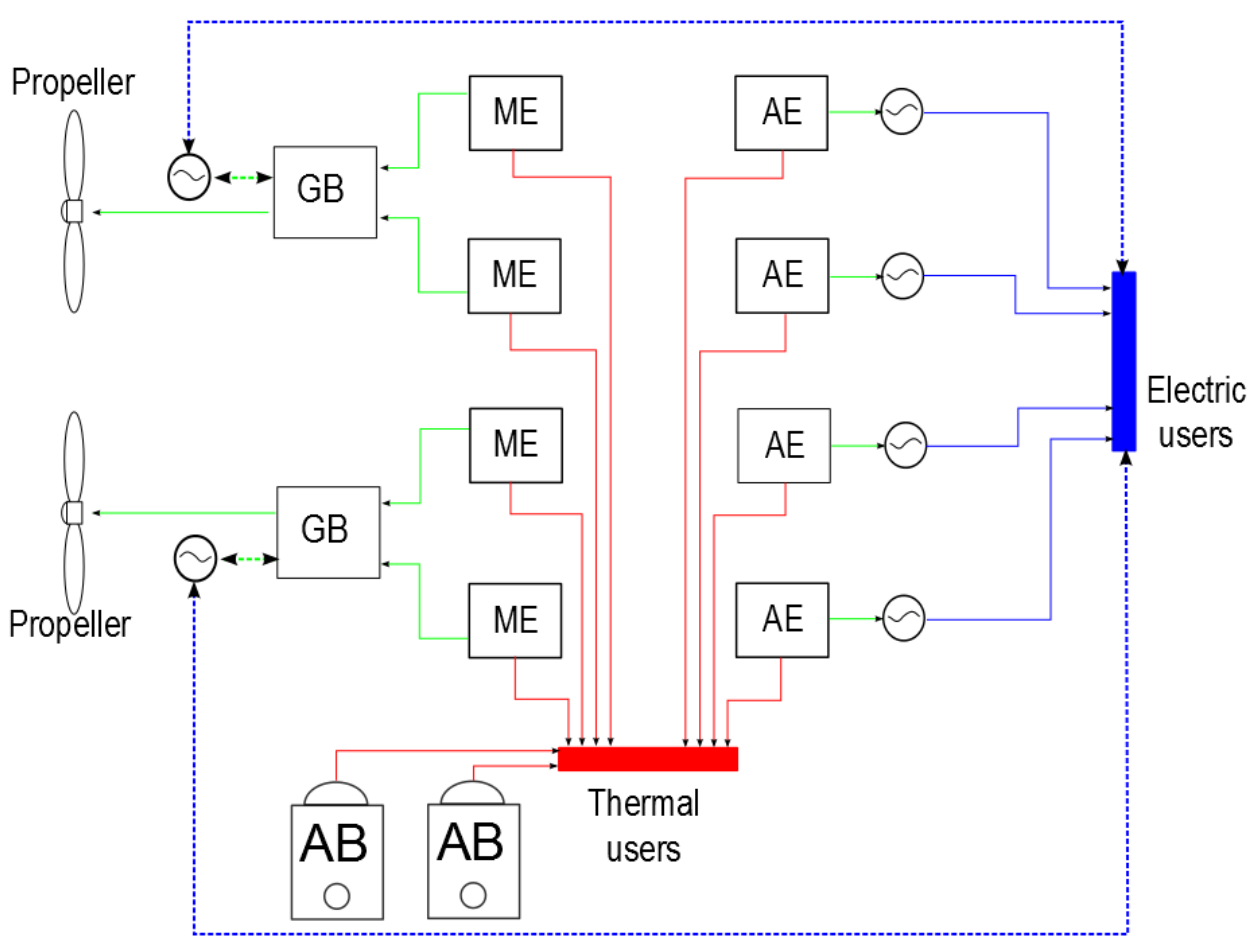

Figure 11: Schematic representation of the case study ship energy system after retrofitting of shaft motors/generators

\section{Model application}

The model proposed in this paper was tested for the optimisation of the power management of the selected case study over one reference voyage. The model input, namely the power demand for propulsion, auxiliary electric and auxiliary heat, is shown in Figure 12 and in Table 3 . The trip represents a reference round-voyage of a total duration of $24 \mathrm{~h}$ including one stop in Stockholm (start- and enddestination, 15-18), one in Mariehamn (intermediate destination, 7-8)) and one, stop in the sea of Åland (0-5) where the ship is not in port but drifting at sea, waiting in order to avoid arriving in Mariehamn too early in the morning.

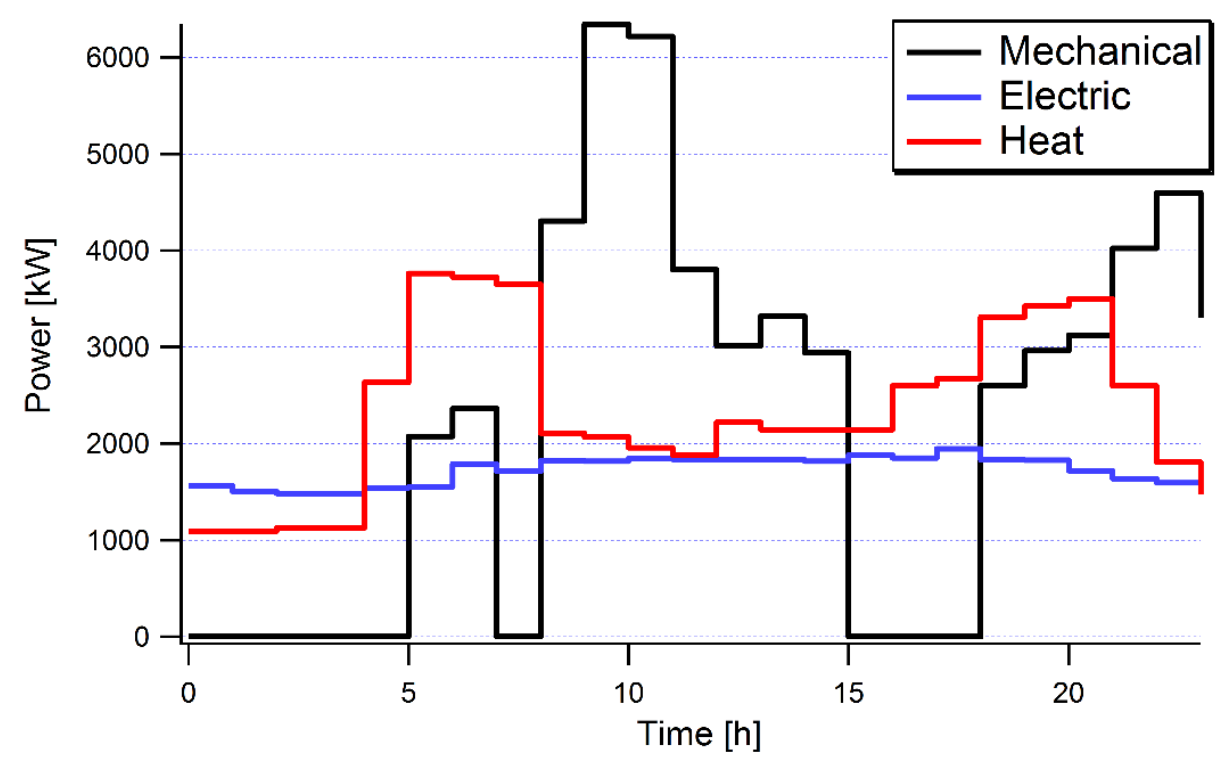

Figure 12: Reference round voyage 
Table 3: Summary of the power demands for the reference voyage

\begin{tabular}{lrrr}
\hline Time $[\mathrm{h}]$ & $P_{\text {mech }}$ & \multicolumn{1}{c}{ Pelectric } & \multicolumn{1}{l}{ Pheat } \\
\hline 0 & 0 & 1563 & 1091 \\
1 & 0 & 1502 & 1091 \\
2 & 0 & 1485 & 1129 \\
3 & 0 & 1476 & 1129 \\
4 & 0 & 1540 & 2634 \\
5 & 2075 & 1551 & 3763 \\
6 & 2363 & 1790 & 3726 \\
7 & 0 & 1713 & 3650 \\
8 & 4305 & 1824 & 2107 \\
9 & 6343 & 1817 & 2070 \\
10 & 6218 & 1844 & 1957 \\
11 & 3800 & 1835 & 1882 \\
12 & 3012 & 1834 & 2220 \\
13 & 3320 & 1834 & 2145 \\
14 & 2940 & 1815 & 2145 \\
15 & 0 & 1880 & 2145 \\
16 & 0 & 1849 & 2597 \\
17 & 0 & 1945 & 2672 \\
18 & 2601 & 1830 & 3312 \\
19 & 2961 & 1828 & 3425 \\
20 & 3125 & 1717 & 3500 \\
21 & 4023 & 1638 & 2597 \\
22 & 4598 & 1593 & 1806 \\
23 & 3303 & 1549 & 1473 \\
24 & 0 & 1563 & 1091 \\
\hline & & &
\end{tabular}

\subsection{MINLP problem setup}

The MINLP problem was setup as shown in Section 2.1. Given that the power plant of the proposed test case has four AEs of the same model, only one group of AEs is considered. The elements of the optimisation independent variable $x$ are summarised in Table 4

Table 4: Summary of the elements of the optimisation vector for the test case vessel

\begin{tabular}{|c|c|c|c|c|c|c|c|c|c|c|c|}
\hline \multicolumn{3}{|c|}{ Main engines (1) } & \multicolumn{3}{|c|}{ Main engines (2) } & \multicolumn{3}{|c|}{ Auxiliary engines } & \multicolumn{3}{|c|}{ Auxiliary boilers } \\
\hline $\mathrm{N}$ & $\mathrm{T}$ & $\mathrm{M}$ & $\mathrm{N}$ & $\mathrm{T}$ & $\mathrm{M}$ & $\mathrm{N}$ & $\mathrm{T}$ & $\mathrm{M}$ & $\mathrm{N}$ & $\mathrm{T}$ & $\mathrm{M}$ \\
\hline$x_{1}$ & 1 & \# running & $x_{2}$ & 1 & \# running & $x_{3}$ & 1 & \# running & $x_{4}$ & 1 & \# running \\
\hline$x_{5}$ & C & $\lambda_{M E 1 \rightarrow \text { prop } 1}$ & $x_{8}$ & C & $\lambda_{M E 2 \rightarrow \text { prop } 1}$ & $x_{11}$ & C & $\lambda_{A E \rightarrow \operatorname{prop} 1}$ & $x_{14}$ & C & $\lambda_{A B \rightarrow \text { heat }}$ \\
\hline$x_{6}$ & C & $\lambda_{M E 1 \rightarrow \text { prop } 2}$ & $x_{9}$ & C & $\lambda_{M E 2 \rightarrow \text { prop } 2}$ & $x_{12}$ & C & $\lambda_{A E \rightarrow \text { prop } 2}$ & & & \\
\hline$x_{7}$ & C & $\lambda_{M E 1 \rightarrow e l}$ & $x_{10}$ & C & $\lambda_{M E 2 \rightarrow e l}$ & $x_{13}$ & $\mathrm{C}$ & $\lambda_{A E \rightarrow e l}$ & & & \\
\hline \multicolumn{12}{|c|}{$\mathrm{N}=$ Variable name } \\
\hline \multicolumn{12}{|c|}{$\mathrm{T}=$ Variable type } \\
\hline \multicolumn{12}{|c|}{$\mathrm{M}=$ Variable meaning } \\
\hline \multicolumn{12}{|c|}{ I = Integer } \\
\hline \multicolumn{12}{|c|}{$\mathrm{C}=$ Continuous } \\
\hline
\end{tabular}




\subsection{Results analysis}

The results of the application of the proposed method to the test case (presented in Section 3, according to the reference voyage as presented in Figure 12) are shown in Table 6 Table 5 and Table 6Table 8 for the baseline and the hybridised power plants, respectively. In particular Table 5Table 7 and Table 8Table 6 Table 6 show, for every time step (fixed to 1 hour), the operational mode (OM) and the number of components running for each of the groups (variables $x_{1}$ to $x_{4}$ for ME1, ME2, AE and AB respectively), the fraction of the MCR of each group going to the corresponding demand $\left(x_{5}, x_{6}\right.$ and $x_{7}$ for the fraction of the MCR of Group ME1 that goes to the first propeller, the second propeller, and the electric demand respectively, and similarly to the other main engines and for the auxiliary engines).

The hybridisation of the system via the installation of reversible shaft generators/motors provides savings, in relation to the reference voyage, of up to $2.9 \%$ compared to the baseline system.

Each point was classified in 4 operating modes:

- ST (standard) mode: Main engines provide power for propulsion, auxiliary engines provide auxiliary electric power

- AE mode: All propulsive and auxiliary power is provided by the auxiliary engines

- ME1 mode: All propulsive and auxiliary power is provided by one group of main engines

- ME2 mode: All propulsive and auxiliary power is provided by two group of main engines

- MIX mode: Power is provided by a mix of main and auxiliary engines

The baseline power plant can only operate in ST mode, while the hybridised power plant allows a larger number of alternative operational modes. Table 6Table 6 shows that the ST mode is the optimal one only when there is no propulsion power demand. This also comes as a consequence of the fact that the auxiliary power demand, both in port and at sea, never exceeds the MCR of one auxiliary engine, and it makes it therefore more convenient not to use the main engines in this mode.

It can be noted that the optimal loads, when both groups of main engines are operated, are not always equally distributed on the two engine groups. This comes as a consequence of the nonlinearity of the efficiency curve of the engines, which can make it more convenient to operate one engine closer to its most efficient point, while leaving the other at low load, and low efficiency.

The resulting lower fuel consumption can be related to a contribution of several factors, as shown in Table 7Table 7. The comparison of the losses in the baseline and hybrid case, broken down to the different groups of components, shows the improvement in the performance of the main and the auxiliary engines, which are operated closer to their most efficient load point. On the other hand, it is also shown that the advantages resulting from the hybridisation of the system are reduced by increased transmission losses, both in the motors/generators and in the gearbox, as well as from additional losses from the boilers. This last point comes from the fact that the engines, being operated at higher efficiency, generate lower losses and therefore lower availability of thermal energy for further use on board.

It should be noted that, in this specific application case, it was imposed that only one of the two ME blocks is able to provide exhaust gas heat. In theory, two HRSGs are installed on the MEs on board: one per propulsion line, making it possible to recover heat from the exhaust gas of two ME simultaneously. This is, in practice, never done on board in order to ensure that all the four main engines are operated for a similar amount of time. 
Table 5: Detail of the load and efficiency of all component groups for the case study vessel and for the reference voyage. Baseline power plant.

\begin{tabular}{|c|c|c|c|c|c|c|c|c|c|c|c|c|c|c|c|c|c|c|c|}
\hline \multirow[t]{2}{*}{ Time } & \multirow[t]{2}{*}{$\mathrm{OM}$} & \multicolumn{5}{|c|}{ Main engines (1) } & \multicolumn{5}{|c|}{ Main engines (2) } & \multicolumn{5}{|c|}{ Auxiliary engines } & \multicolumn{3}{|c|}{ Aux. Boilers } \\
\hline & & $x_{1}$ & $x_{5}$ & $x_{6}$ & $x_{7}$ & $\eta$ & $x_{2}$ & $x_{8}$ & $x_{9}$ & $x_{10}$ & $\eta$ & $x_{3}$ & $x_{11}$ & $x_{12}$ & $x_{13}$ & $\eta$ & $x_{4}$ & $x_{14}$ & $\eta$ \\
\hline 1 & ST & 0 & - & - & - & - & 0 & - & - & - & - & 1 & 0 & 0 & 0.62 & 0.43 & 0 & - & - \\
\hline 2 & ST & 0 & - & - & - & - & 0 & - & - & - & - & 1 & 0 & 0 & 0.59 & 0.43 & 0 & - & - \\
\hline 3 & ST & 0 & - & - & - & - & 0 & - & - & - & - & 1 & 0 & 0 & 0.59 & 0.43 & 0 & - & - \\
\hline 4 & ST & 0 & - & - & - & - & 0 & - & - & - & - & 1 & 0 & 0 & 0.58 & 0.43 & 0 & - & - \\
\hline 5 & ST & 0 & - & - & - & - & 0 & - & - & - & - & 1 & 0 & 0 & 0.61 & 0.43 & 1 & 0.36 & 0.85 \\
\hline 6 & ST & 1 & 0.19 & 0 & 0 & 0.37 & 1 & 0 & 0.19 & 0 & 0.37 & 1 & 0 & 0 & 0.61 & 0.43 & 1 & 0.14 & 0.85 \\
\hline 7 & ST & 1 & 0.22 & 0 & 0 & 0.38 & 1 & 0 & 0.22 & 0 & 0.38 & 2 & 0 & 0 & 0.36 & 0.43 & 1 & 0.29 & 0.85 \\
\hline 8 & ST & 0 & - & - & - & - & 0 & - & - & - & - & 1 & 0 & 0 & 0.67 & 0.43 & 2 & 0.30 & 0.85 \\
\hline 9 & ST & 1 & 0.39 & 0 & 0 & 0.42 & 1 & 0 & 0.39 & 0 & 0.42 & 1 & 0 & 0 & 0.72 & 0.43 & 0 & - & 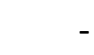 \\
\hline 10 & ST & 1 & 0.58 & 0 & 0 & 0.45 & 1 & 0 & 0.58 & 0 & 0.45 & 1 & 0 & 0 & 0.71 & 0.43 & 0 & - & - \\
\hline 11 & ST & 1 & 0.56 & 0 & 0 & 0.45 & 1 & 0 & 0.56 & 0 & 0.45 & 1 & 0 & 0 & 0.72 & 0.43 & 0 & - & - \\
\hline 12 & ST & 1 & 0.35 & 0 & 0 & 0.41 & 1 & 0 & 0.35 & 0 & 0.41 & 1 & 0 & 0 & 0.72 & 0.43 & 0 & - & - \\
\hline 13 & ST & 1 & 0.27 & 0 & 0 & 0.40 & 1 & 0 & 0.27 & 0 & 0.40 & 1 & 0 & 0 & 0.72 & 0.43 & 0 & - & - \\
\hline 14 & ST & 1 & 0.30 & 0 & 0 & 0.40 & 1 & 0 & 0.30 & 0 & 0.40 & 1 & 0 & 0 & 0.72 & 0.43 & 0 & - & - \\
\hline 15 & ST & 1 & 0.27 & 0 & 0 & 0.39 & 1 & 0 & 0.27 & 0 & 0.39 & 1 & 0 & 0 & 0.72 & 0.43 & 0 & - & - \\
\hline 16 & ST & 0 & - & - & - & - & 0 & - & - & - & - & 1 & 0 & 0 & 0.74 & 0.43 & 1 & 0.20 & 0.85 \\
\hline 17 & ST & 0 & - & - & - & - & 0 & - & - & - & - & 2 & 0 & 0 & 0.74 & 0.43 & 1 & 0.22 & 0.85 \\
\hline 18 & ST & 0 & - & - & - & - & 0 & - & - & - & - & 1 & 0 & 0 & 0.76 & 0.43 & 1 & 0.32 & 0.85 \\
\hline 19 & ST & 1 & 0.24 & 0 & 0 & 0.39 & 1 & 0 & 0.24 & 0 & 0.39 & 1 & 0 & 0 & 0.72 & 0.43 & 0 & 0.16 & 0.85 \\
\hline 20 & ST & 1 & 0.28 & 0 & 0 & 0.39 & 1 & 0 & 0.28 & 0 & 0.39 & 1 & 0 & 0 & 0.72 & 0.43 & 0 & 0.16 & 0.85 \\
\hline 21 & ST & 1 & 0.29 & 0 & 0 & 0.40 & 1 & 0 & 0.29 & 0 & 0.40 & 1 & 0 & 0 & 0.67 & 0.43 & 0 & 0.19 & 0.85 \\
\hline 22 & ST & 1 & 0.37 & 0 & 0 & 0.42 & 1 & 0 & 0.37 & 0 & 0.42 & 1 & 0 & 0 & 0.64 & 0.43 & 0 & - & - \\
\hline 23 & ST & 1 & 0.42 & 0 & 0 & 0.43 & 1 & 0 & 0.42 & 0 & 0.43 & 1 & 0 & 0 & 0.63 & 0.43 & 0 & - & \\
\hline 24 & ST & 1 & 0.30 & 0 & 0 & 0.40 & 1 & 0 & 0.30 & 0 & 0.40 & 1 & 0 & 0 & 0.61 & 0.43 & 0 & - & \\
\hline
\end{tabular}


Table 6: Detail of the load and efficiency of all component groups for the case study vessel and for the reference voyage. Hybridised power plant

\begin{tabular}{|c|c|c|c|c|c|c|c|c|c|c|c|c|c|c|c|c|c|c|c|}
\hline \multirow[t]{2}{*}{ Time } & \multirow[t]{2}{*}{ OM } & \multicolumn{5}{|c|}{ Main engines (1) } & \multicolumn{5}{|c|}{ Main engines (2) } & \multicolumn{5}{|c|}{ Auxiliary engines } & \multicolumn{3}{|c|}{ Aux. Boilers } \\
\hline & & $x_{1}$ & $x_{5}$ & $x_{6}$ & $x_{7}$ & $\eta_{M E 1}$ & $x_{2}$ & $x_{8}$ & $x_{9}$ & $x_{10}$ & $\eta_{M E 2}$ & $x_{3}$ & $x_{11}$ & $x_{12}$ & $x_{13}$ & $\eta_{A E}$ & $x_{4}$ & $x_{14}$ & $\eta_{A B}$ \\
\hline 1 & ST & 0 & - & - & - & - & 0 & - & - & - & - & 1 & 0.00 & 0.00 & 0.62 & 0.43 & 0 & - & - \\
\hline 2 & ST & 0 & - & - & - & - & 0 & - & - & - & - & 1 & 0.00 & 0.00 & 0.59 & 0.43 & 0 & - & - \\
\hline 3 & ST & 0 & - & - & - & - & 0 & - & - & - & - & 1 & 0.00 & 0.00 & 0.59 & 0.43 & 0 & - & - \\
\hline 4 & ST & 0 & - & - & - & - & 0 & - & - & - & - & 1 & 0.00 & 0.00 & 0.58 & 0.43 & 0 & - & - \\
\hline 5 & ST & 0 & - & - & - & - & 0 & - & - & - & - & 1 & 0.00 & 0.00 & 0.61 & 0.43 & 1 & 0.36 & 0.85 \\
\hline 6 & MIX & 1 & 0.19 & 0.00 & 0.00 & 0.37 & 0 & - & - & - & - & 2 & 0.00 & 0.25 & 0.31 & 0.42 & 1 & 0.14 & 0.85 \\
\hline 7 & MIX & 1 & 0.22 & 0.00 & 0.00 & 0.38 & 0 & - & - & - & - & 3 & 0.00 & 0.19 & 0.24 & 0.41 & 0 & - & - \\
\hline 8 & ST & 0 & - & - & - & - & 0 & - & - & - & - & 1 & 0.00 & 0.00 & 0.67 & 0.43 & 2 & 0.30 & 0.85 \\
\hline 9 & ME2 & 1 & 0.39 & 0.00 & 0.34 & 0.46 & 1 & 0.00 & 0.40 & 0.03 & 0.43 & 0 & - & - & - & - & 0 & - & - \\
\hline 10 & ME2 & 1 & 0.58 & 0.00 & 0.18 & 0.46 & 1 & 0.00 & 0.58 & 0.18 & 0.46 & 0 & - & - & - & - & 0 & - & - \\
\hline 11 & ME2 & 1 & 0.56 & 0.00 & 0.19 & 0.46 & 1 & 0.00 & 0.56 & 0.19 & 0.46 & 0 & - & - & - & - & 0 & - & - \\
\hline 12 & ME2 & 1 & 0.35 & 0.00 & 0.34 & 0.46 & 1 & 0.00 & 0.35 & 0.03 & 0.42 & 0 & - & - & - & - & 0 & - & - \\
\hline 13 & MIX & 1 & 0.27 & 0.00 & 0.32 & 0.45 & 1 & 0.00 & 0.28 & 0.00 & 0.40 & 1 & 0.00 & 0.00 & 0.10 & 0.37 & 0 & - & - \\
\hline 14 & ME2 & 1 & 0.30 & 0.00 & 0.34 & 0.46 & 1 & 0.00 & 0.31 & 0.03 & 0.41 & 0 & - & - & - & - & 0 & - & - \\
\hline 15 & ME2 & 1 & 0.27 & 0.05 & 0.29 & 0.45 & 1 & 0.00 & 0.23 & 0.08 & 0.40 & 0 & - & - & - & - & 0 & - & - \\
\hline 16 & ST & 0 & - & - & - & - & 0 & - & - & - & - & 1 & 0.00 & 0.00 & 0.74 & 0.43 & 1 & 0.20 & 0.85 \\
\hline 17 & ST & 0 & - & - & - & - & 0 & - & - & - & - & 2 & 0.00 & 0.00 & 0.74 & 0.41 & 1 & 0.22 & 0.85 \\
\hline 18 & ST & 0 & - & - & - & - & 0 & - & - & - & - & 1 & 0.00 & 0.00 & 0.76 & 0.43 & 1 & 0.32 & 0.85 \\
\hline 19 & MIX & 1 & 0.24 & 0.00 & 0.00 & 0.39 & 0 & - & - & - & - & 2 & 0.00 & 0.31 & 0.36 & 0.43 & 0 & - & - \\
\hline 20 & MIX & 1 & 0.27 & 0.00 & 0.00 & 0.39 & 0 & - & - & - & - & 2 & 0.00 & 0.35 & 0.36 & 0.43 & 0 & - & - \\
\hline 21 & MIX & 1 & 0.29 & 0.00 & 0.00 & 0.40 & 1 & 0.00 & 0.10 & 0.00 & 0.35 & 2 & 0.00 & 0.24 & 0.34 & 0.43 & 0 & - & - \\
\hline 22 & MIX & 1 & 0.37 & 0.00 & 0.27 & 0.46 & 1 & 0.00 & 0.37 & 0.00 & 0.42 & 1 & 0.00 & 0.00 & 0.13 & 0.38 & 0 & - & - \\
\hline 23 & ME2 & 1 & 0.42 & 0.00 & 0.32 & 0.46 & 1 & 0.00 & 0.42 & 0.00 & 0.43 & 0 & - & - & - & - & 0 & - & - \\
\hline 24 & ME2 & 1 & 0.30 & 0.00 & 0.31 & 0.45 & 1 & 0.00 & 0.30 & 0.00 & 0.40 & 0 & - & - & - & - & 0 & - & - \\
\hline
\end{tabular}


Table 7: Breakdown of the conversion and transmission losses during the reference voyage, comparison between baseline and hybrid system. All values are presented in GJ

\begin{tabular}{|c|c|c|c|}
\hline Losses in: & Baseline & Hybrid & Difference \\
\hline Main engines & 333,00 & 432,00 & \\
\hline Auxiliary engines & 231,00 & 103,00 & $-28,600$ \\
\hline Auxiliary boilers & 4,25 & 4,25 & 0,000 \\
\hline Gearbox & 10,50 & 12,99 & 2,500 \\
\hline SG/SMs & 6,38 & 6,71 & 0,330 \\
\hline Frequency converters & 0,00 & 1,49 & 1,490 \\
\hline
\end{tabular}

\subsection{Shaft motor/generator dimensioning}

The results presented in the previous section relate to the installation of a SG/SM rated $2000 \mathrm{~kW}$ on each propulsion line. The analysis of the optimal dimensioning of the size of the SM/SG is hereby presented.

The maximum savings are achieved for an installed SG/SM power of $2000 \mathrm{~kW}$, as for higher installed SG/SM power the effect of decreasing efficiency when operated at part-load becomes relevant and is not balanced by increased benefits (see Figure 13).

Figure 13 also shows the results of the installation of an SG/SM on only one of the two propulsion lines. This allows only one of the two groups of main engines to be used for auxiliary electric power generation, while not allowing engine group 1 to transfer mechanical power to propeller 2 and vice versa. It can be noticed that although savings are lower, it would still be possible to achieve an estimated $2.3 \%$ fuel savings.

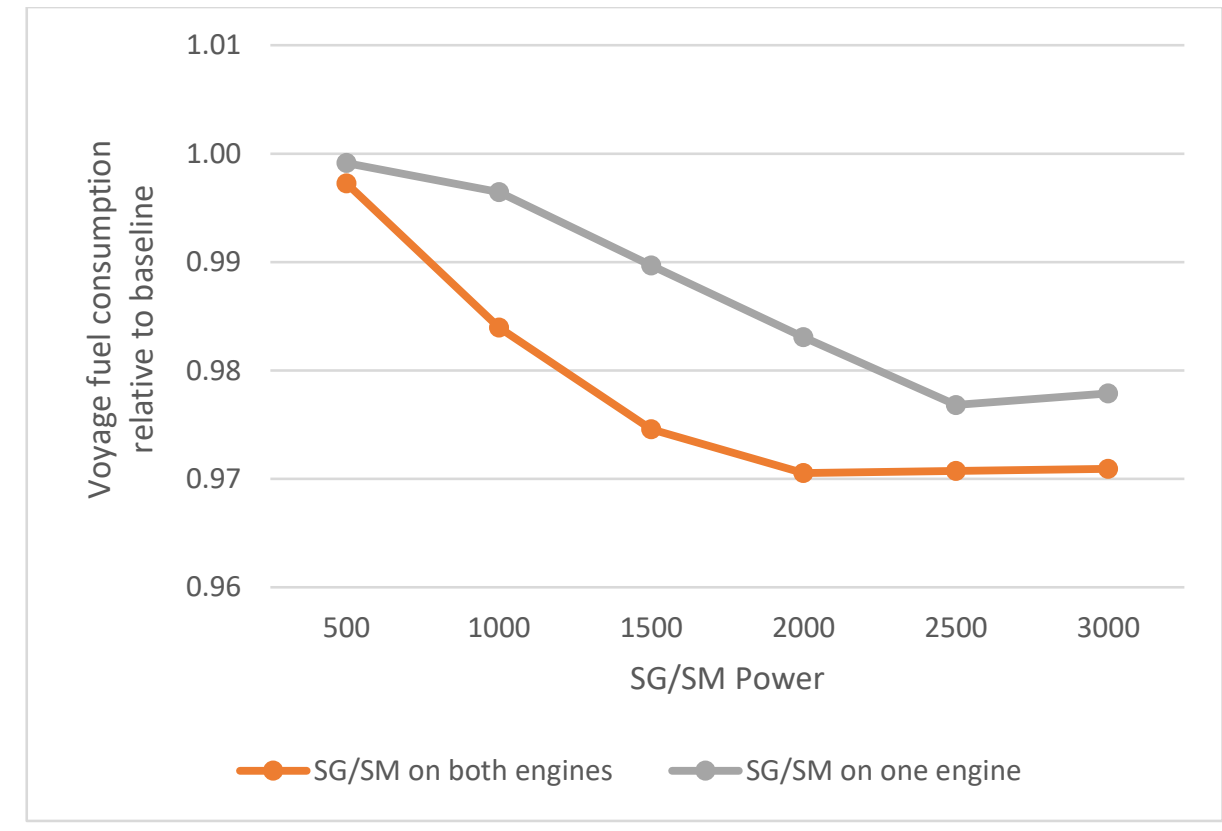

Figure 13: Calculated voyage fuel consumption versus installed SG/SM power

The energetic performance of the hybrid system suggests that the largest benefits can be achieved when SG/SM are installed on both shaft lines, for an installed power of approximately $2000 \mathrm{MW}$ per machine. The solution with the SG/SM on only one shaft line, although promising, does not lead to a decreased fuel consumption in the same magnitude. 
The NPV of the system retrofit was calculated based on a 5\% interest rate [55], a fuel price of 300 USD/ton and a time horizon of 5 and 10 years. The cost function proposed by Astolfi et al. [56] for electric generators was used to estimate the dependence of capital costs on installed power, not considering the cost of installation of considering a retrofit.

From results of the economic analysis, it appears that (see Figure 14):

- For having a positive NPV it is required to install at least a certain size for the SG/SM (above $1000 \mathrm{~kW}$ each for installation on two shaft lines, above $1600 \mathrm{~kW}$ for installation on only one shaft line in the 5 year case).

- The installation of a SG/SM on only one of the two shaft lines is more economically convenient for the investigated time horizons. The difference is more pronounced for the 5-years horizon.

- For the case where the SG/SM is installed on only one propulsion line, the optimal MCR does not change with the time horizon and is located around $2250 \mathrm{~kW}$ of installed power.

- For the case where the SG/SM is installed on both propulsion lines, the optimum point moves towards higher installed power (from approx. $1250 \mathrm{~kW}$ to approx. $1500 \mathrm{~kW}$ ) with increased time horizon

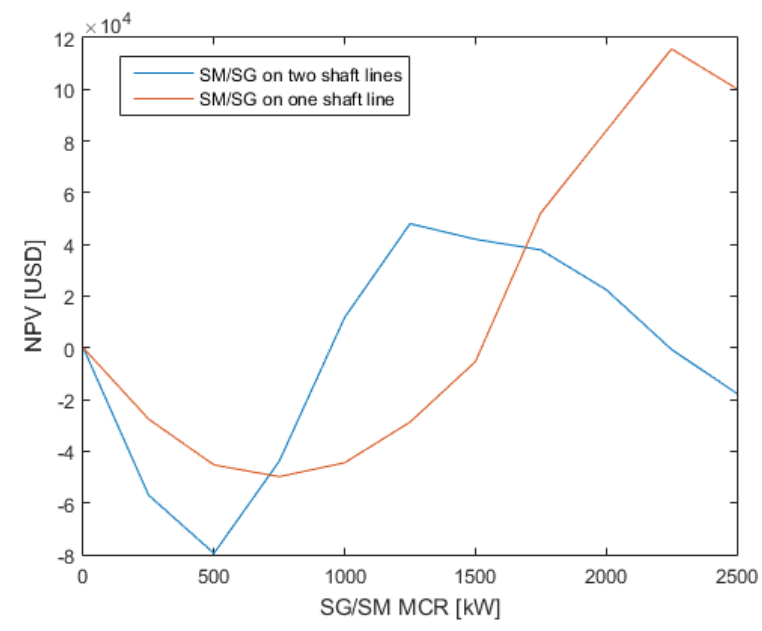

(a) 5-years horizon

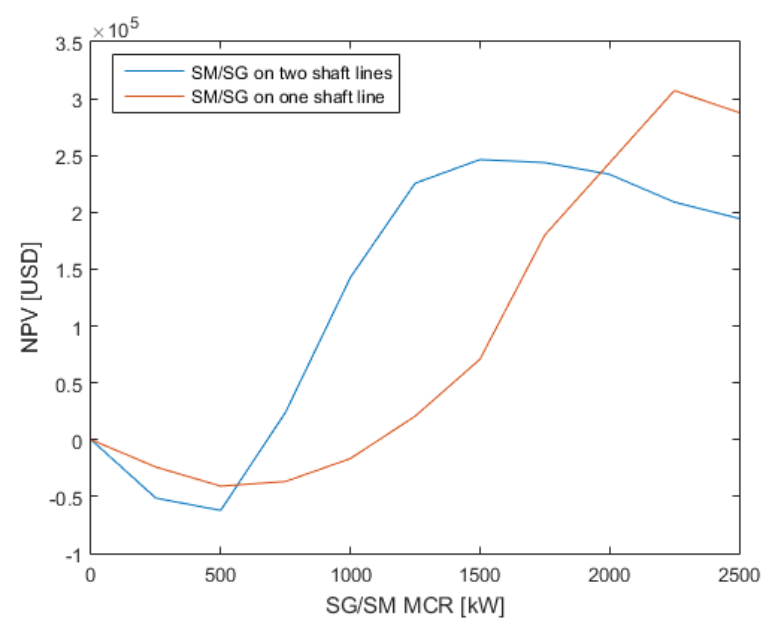

(b) 10-years horizon

Figure 14: NPV of the hybridised system as a function of the installed power of the SG/SM

\subsection{The relevance of thermal power demand}

Compared to the work already published in scientific literature, such as what presented by Kanellos et al. [32], the present work proposed as element of innovation the inclusion of the thermal energy demand in the constraints to be fulfilled by the load-allocation algorithm, and the fuel consumption from the oil-fired boilers to the objective function to be minimised.

Figure 15 presents the comparison of the fuel consumption resulting from the use of the optimisation algorithm with and without the presence of the oil-fired boilers contribution to the objective function. The results presented in Figure 15 refer to the hybridised system: the conditions imposed in the baseline system the load allocation problem do not allow sufficient flexibility for benefiting from an improved load allocation procedure.

When the ship is sailing, more than sufficient waste heat is available from the main engines as to make boilers operations unnecessary in both cases. When the ship is in port, however (see. 5-6 AM and 6-8 PM in Figure 15: Comparison of the fuel consumption for the reference voyage. The ), only the auxiliary 
engines are running and, therefore, the oil-fired boilers are used. In these conditions, the optimisation of the load allocation is also influenced by the need of satisfying the demand for thermal power on board.

The improvement in the performance of the system is estimated to reach up to roughly $3 \%$, compared to an optimisation where the thermal element of on board energy demand is not considered. This can also be seen in the different load allocation in the two cases, as shown in Table 8. It can be seen in particular in the cases of 6-8 PM that the load allocation algorithm that takes into account the fuel consumption of the boilers adjusts the load on the engines to avoid running the boilers.

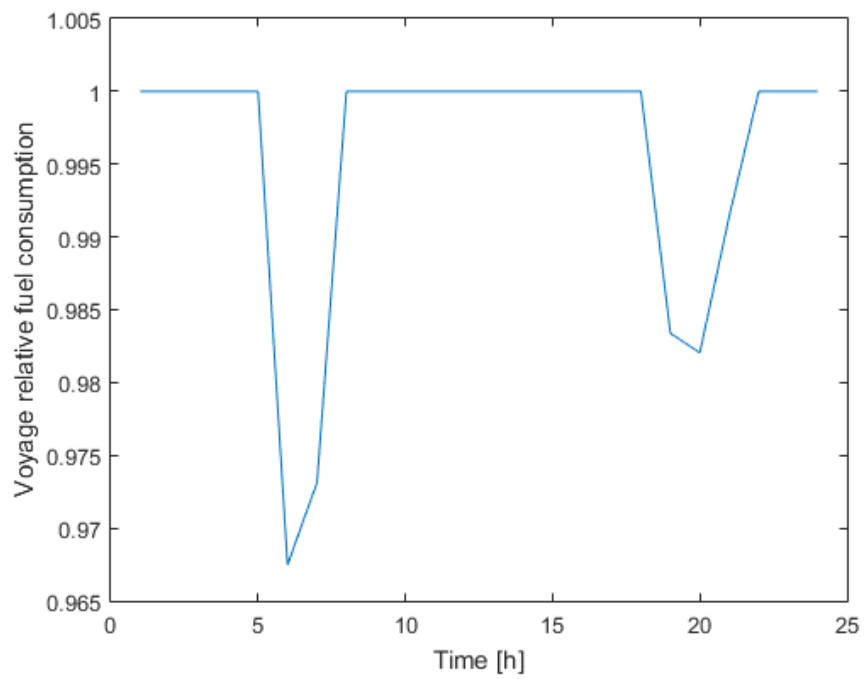

Figure 15: Comparison of the fuel consumption for the reference voyage. The value on the $Y$ axis represents the ratio between the ship fuel consumption when the load sharing is optimised including boilers fuel consumption, and the ship fuel consumption when the boilers' fuel consumption is not included in the optimisation.

Table 8: Comparison of the load distribution when the fuel consumption of the auxiliary boiler is included or not.

\begin{tabular}{|c|c|c|c|c|c|c|c|c|}
\hline \multirow{3}{*}{ Time } & \multicolumn{8}{|c|}{ Load } \\
\hline & \multicolumn{4}{|c|}{$\dot{m}_{A B}$ not included in $f_{o b j}$} & \multicolumn{4}{|c|}{$\dot{m}_{A B}$ included in $f_{o b j}$} \\
\hline & $\mathrm{ME}(1)$ & ME (2) & $\mathrm{AE}$ & $A B$ & ME (1) & $\mathrm{ME}(2)$ & $\mathrm{AE}$ & $A B$ \\
\hline 6 & $50 \%(1)$ & $19 \%(1)$ & $0 \%(0)$ & $27 \%(1)$ & $19 \%(1)$ & $19 \%(1)$ & $61 \%(1)$ & $14 \%(1)$ \\
\hline 7 & $56 \%(1)$ & $24 \%$ (1) & $0 \%(0)$ & $20 \%(1)$ & $22 \%(1)$ & $22 \%(1)$ & $68 \%(1)$ & $0 \%(0)$ \\
\hline 19 & $58 \%(1)$ & $27 \%(1)$ & $0 \%(0)$ & $10 \%(1)$ & $52 \%(1)$ & $24 \%(1)$ & $17 \%(1)$ & $0 \%(0)$ \\
\hline 20 & $61 \%$ (1) & $30 \%$ (1) & $0 \%(0)$ & $10 \%$ (1) & $57 \%$ (1) & $27 \%$ (1) & $15 \%$ (1) & $0 \%(0)$ \\
\hline
\end{tabular}

\subsection{Further considerations}

The results presented in Sections 4.2 to 4.4 related to the sole aspects related to energy and fuel consumption. Hereafter some issues are discussed that, although not strictly related to the efficiency of engines and boilers, have an impact of the behaviour of the whole power plant.

Maximising the safety of ship operations often brings to conflicting interests with energy efficiency. On the specific ship under study, for instance, it has been observed that when the ship is operating in some conditions (for instance when manoeuvring in port) it is preferred to run two auxiliary engines at low load instead of one at high load in order to provide redundancy in the failure of one of the two 
engines. This type of operational constraints, which can vary from ship to ship, are not included in the presented load-optimisation method, and the possibility to add such a constraint to the problem formulation should be seen as a way to further improve the validity of the results.

Engine operations at low load were restricted by imposing a low limit on the engine loading, which was namely not allowed to be lower than $10 \%$ of the MCR. In practice, low-load operations are in general demanding on the engines and should be avoided in order to reduce engine wear. The method presented in this work does not account for this aspect, and the addition of soft constraints for disincentivising low-load operations can be also consider as a further addition to the model.

The importance of the heat demand, especially for those conditions in which it is required to run the auxiliary boilers at very low load, was highlighted by the results of this work. This would suggest that additional solutions for improving energy efficiency on board from the heat demand side could be implemented. In particular, energy storage (as proposed for a different ship type in previous work by the authors [57]) and demand-side management are seen as possible solutions that could bring to improvements in the efficiency of the power plant with limited costs and efforts.

\section{Conclusion}

In this paper, a method for optimising the load allocation of the different prime movers for an isolated system characterised by independent demands of mechanical, electric and thermal power is presented. The method consists of the use of simplified nonlinear correlations for the efficiency of the individual components, and of the definition of a MINLP problem to be solved with a combination of SQP and branch-and-bound methods.

The proposed method was applied to the power plant of a cruise ship sailing in the Baltic Sea, characterised by a time-dependent demand of mechanical power (for propulsion), electric power (for on board auxiliaries and accommodation) and thermal power (for accommodation and other facilities).

The application of the method showed its ability to identify the optimal load allocation for the different prime movers. The results showed the importance of including thermal power demand into account, which can lead to fuel savings of up to $3 \%$ compared to the case where this demand is not accounted for.

Furthermore, the method was applied to the possibility of improving the efficiency of the power plant by installing shaft generators/motors. The proposed method allows handling the increased level of complexity of the system, where the additional interconnections within the system would allow for the on board power demands to be fulfilled in many different combinations of prime movers. This allowed evaluating the performance of the retrofitted system, which showed the possibility for up to $3 \%$ yearly savings in fuel consumption, and identifying the optimal installed power for maximising the NPV of the system.

\section{Acknowledgments}

The authors of this paper would like to thank the Swedish Energy Agency (Energimyndigheten) and the Swedish Maritime Administration (Sjöfartsverket) for their financial support. The authors of this paper would also like to thank Eckerö Rederiet, and in particular the crew of MS Birka Stockholm, for sharing the data, information and experience that was crucial for this work. 


\section{Bibliography}

[1] Smith TWP, Jalkanen JP, Anderson BA, Corbett JJ, Faber J, Hanayama S, et al. Third IMO GHG Study. London, UK: 2014.

[2] Anderson K, Bows A. Executing a Scharnow turn: reconciling shipping emissions with international commitments on climate change. Carbon Manag 2012;3:615-28.

[3] MEPC. Resolution MEPC.203(62). London, United Kingdom: Maritime Environmental Protection Committee (MEPC), part of the International Maritime Organisation (IMO); 2011.

[4] EC. Roadmap to a Single European Transport Area - Towards a competitive and resource efficient transport system. Brussels, Belgium: 2011.

[5] Norstad I, Fagerholt K, Laporte G. Tramp ship routing and scheduling with speed optimization. Transp Res Part C Emerg Technol 2011;19:853-65.

[6] Nishida T, Katori M, Uzawa K, Ohuchi K, Waseda T. Optimization of Integrated Weather Routing Systems for Sailing Cargo Ships. Proceeding 21st Int. Offshore Polar Eng. Conf., vol. 8, Maui, USA: 2011, p. 283-9.

[7] Shao W, Zhou P, Thong SK. Development of a novel forward dynamic programming method for weather routing. J Mar Sci Technol 2006;11:239-51.

[8] Kim H, Choi SS, Hong C, Yoo S, Seo J, Hwangbo S, et al. Development and Application of Trim Optimization and Parametric techniques Using an Evaluation System (SoLuTion) Based on the RANS for Improvement of EEOI. Vol. 2 CFD VIV, vol. 2, ASME; 2013, p. 784-91.

[9] Moustafa MM, Yehia W, Hussein AW. Energy efficient operation of bulk carriers by trim optimization. In: Altosole M, Francescutto A, editors. Proc. 18th Int. Conf. Ships Shipp. Res., Lecco, Italy: 2015.

[10] Petersen JP, Winther O, Jacobsen DJ. A machine-learning approach to predict main energy consumption under realistic operational conditions. Sh Technol Res 2012;59:64-72.

[11] Cariou P. Is slow steaming a sustainable means of reducing CO2 emissions from container shipping? Transp Res Part D Transp Environ 2011;16:260-4.

[12] Guan C, Theotokatos G, Zhou P, Chen H. Computational investigation of a large containership propulsion engine operation at slow steaming conditions. Appl Energy 2014;130:370-83.

[13] Kindt S. State-of-the-art MAN B \& W Two-stroke Super-long-stroke Engines. Proc Congr Int Counc Combust Engines 2013.

[14] Imperato M. Some Experimental Experience Gained With a Medium-Speed Diesel Research Engine. Proc. Congr. Int. Counc. Combust. Engines, 2010. 
[15] Risse S, Gmbh KB, Buchmann K. New turbochargers for modern large engines with low emissions and high performance. Proc. Congr. Int. Counc. Combust. Engines, 2013.

[16] Aesoy V, Magne Einang P, Stenersen D, Hennie E, Valberg I. LNG-Fuelled Engines and Fuel Systems for Medium-Speed Engines in Maritime Applications 2011.

[17] Xie G. Optimal preliminary propeller design based on multi-objective optimization approach. Procedia Eng., vol. 16, 2011, p. 278-83.

[18] Motley MR, Nelson M, Young YL. Integrated probabilistic design of marine propulsors to minimize lifetime fuel consumption. Ocean Eng 2012;45:1-8.

[19] Hochkirch K, Heimann J, Bertram V. Hull optimization for operational profile - the next game level. V Int. Conf. Comput. Methods Mar. Eng., 2013.

[20] Traut M, Gilbert P, Walsh C, Bows A, Filippone A, Stansby P, et al. Propulsive power contribution of a kite and a Flettner rotor on selected shipping routes. Appl Energy 2014;113:362-72.

[21] Viola IM, Sacher M, Xu J, Wang F. A numerical method for the design of ships with wind-assisted propulsion. Ocean Eng 2015;105:33-42.

[22] Dimopoulos GG, Stefanatos IC, Kakalis NMP. Exergy analysis and optimisation of a marine molten carbonate fuel cell system in simple and combined cycle configuration. Energy Convers Manag 2015.

[23] Yang Min-Hsiung YR-H. Analyzing the optimization of an organic Rankine cycle system for recovering waste heat from a large marine engine containing a cooling water system. Energy Convers Manag 2014;88:999-1010.

[24] Nielsen RF, Haglind F, Larsen U. Design and modeling of an advanced marine machinery system including waste heat recovery and removal of sulphur oxides. Energy Convers Manag 2014;85.

[25] Baldi F, Larsen U, Gabrielii C. Comparison of different procedures for the optimisation of a combined Diesel engine and organic Rankine cycle system based on ship operational profile. Ocean Eng 2015;110:85-93.

[26] Kim K, Yang KW, Jeong S, Nam K, Chang D. Absorption refrigeration system utilising engine exhaust gas for bulk gas carriers. Ships Offshore Struct 2013;9:380-6.

[27] Ouadha A, El-Gotni Y. Integration of an ammonia-water absorption refrigeration system with a marine Diesel engine: A thermodynamic study. Procedia Comput Sci 2013;19:754-61.

[28] Woud HK, Stapersma D. Design of Propulsion and Electric Power Generation Systems. Imarest Publications; 2003.

[29] Sciberras EA, Zahawi B, Atkinson DJ, Juandó A. Electric auxiliary propulsion for 
improved fuel efficiency and reduced emissions. Proc Inst Mech Eng Part M J Eng Marit Environ 2013:1-9.

[30] Solem S, Fagerholt K, Erikstad SO, Patricksson Ø. Optimization of diesel electric machinery system configuration in conceptual ship design. J Mar Sci Technol 2015;20:406-16.

[31] Vučetić D, Tomas V, Cuculić A. Electric propulsion optimization model based on exploitation profi le and energy price. Model Optim Električne Propulzije Na Bazi Eksploat Profi La I Cijene Energ 2011;62:130-5.

[32] Kanellos FD, Prousalidis JM, Tsekouras GJ. Control system for fuel consumption minimization-gas emission limitation of full electric propulsion ship power systems. Proc Inst Mech Eng, Part M J Eng Marit Environ 2012;228:17-28.

[33] Baldi F, Johnson H, Gabrielii C, Andersson K. Energy and exergy analysis of ship energy systems: the case study of a chemical tanker. Int J Thermodyn 2015;18:82-93.

[34] Shu G, Liang Y, Wei H, Tian H, Zhao J, Liu L. A review of waste heat recovery on two-stroke IC engine aboard ships. Renew Sustain Energy Rev 2013;19:385-401.

[35] Singh DV, Pedersen E. A review of waste heat recovery technologies for maritime applications. Energy Convers Manag 2016;111:315-28.

[36] Soffiato M, Frangopoulos CA, Manente G, Rech S, Lazzaretto A. Design optimization of ORC systems for waste heat recovery on board a LNG carrier. Energy Convers Manag 2015;92:523-34.

[37] Baldi F, Ahlgren F, Nguyen T-V, Gabrielii C, Andersson K. Energy and Exergy Analysis of cruise ship. Proceeding 28th Int. Conf. Effic. Cost, Optim. Simul. Environ. Impact Energy Syst., Pau, France: 2015.

[38] Baldi F. Modelling, analysis and optimisation of ship energy systems. Chalmers University of Technology, 2016.

[39] Ancona MA, Bianchi M, Branchini L, De Pascale A, Melino F, Orlandini V, et al. Generation side management in smart grid. Proc. ASME-ATI-UIT 2015, Conf. Therm. Energy Syst. Prod. Storage, Util. Environ., Naples, Italy: 2015.

[40] Bengtsson S, Andersson K, Fridell E. A comparative life cycle assessment of marine fuels: liquified natural gas ahd three other fossil fuels. Proc Inst Mech Eng Part M J Eng Marit Environ 2011:Vol 225, Iss 2, pp 97-110.

[41] Rao SS. Engineering optimization: Theory and practice. 4th ed. Hoboken, US: John Wiley \& Sons; 2009.

[42] Leyffer S. Integrating SQP and branch-and-bound for mixed integer nonlinear programming. Comput Optim Appl 2001;18:295-309.

[43] Standardization I organization for. ISO 3046:2002 - Reciprocating internal combustion 
enines - Performance. 2002.

[44] Hiereth H, Prenninger P. Charging the internal combustion engine. Vienna, Austria: Springer-Verlag; 2003.

[45] Snow DA. Plant Engineer's Reference Book. 2001.

[46] Cohen L, Fritz WA. Efficiency determination of marine boilers: input-output versus heat-loss method. J Eng Power 1962;January:39-43.

[47] McCarthy WL, Peters WS, Rodger DR. Marine Diesel power plant practices. Jersey City, US: 1990.

[48] Shi W, Stapersma D, Grimmelius HT. Analysis of energy conversion in ship propulsion system in off-design operation conditions. WIT Trans Econogy Environ 2009;121:461-72.

[49] Dedes E, Hudson DA, Turnock SR. Assessing the potential of hybrid energy technology to reduce exhaust emissions from global shipping. Energy Policy 2012;40:204-18.

[50] Ådanes AK. Maritime electrical installations and Diesel Electric propulsion. ABB AS Marine; 2003.

[51] Adachi M, Kosaka H, Fukuda T, Ohashi S, Harumi K. Economic analysis of transocean LNG-fueled container ship. J Mar Sci Technol 2014.

[52] Astolfi M, Romano MC, Bombarda P, Macchi E. Binary ORC (Organic Rankine Cycles) power plants for the exploitation of medium-low temperature geothermal sources - Part B: Techno-economic optimization. Energy 2014;66:435-46.

[53] Baldi F, Gabrielii C, Melino F, Bianchi M. A preliminary study on the application of thermal storage to merchant ships. Proc. 7th Int. Conf. Appl. Energy, Abu Dhabi, UAE: 2015.

\section{Nomenclature}

$\begin{array}{llll}\text { Abbreviations } & & \mathrm{CO}_{2} & \text { Carbon dioxide } \\ \mathrm{AB} & \text { Auxiliary boiler } & \mathrm{GB} & \text { Gearbox } \\ \mathrm{AE} & \text { Auxiliary engine } & & \end{array}$




\begin{tabular}{|c|c|c|c|}
\hline HRSG & $\begin{array}{l}\text { Heat recovery steam } \\
\text { generator }\end{array}$ & $\begin{array}{l}\text { Subscripts } \\
\text { ca }\end{array}$ & Charge air \\
\hline HT & High temperature & cyl & Cylinder \\
\hline LHV & Lower heating value & des & Design \\
\hline LT & Low temperature & eg & Exhaust gas \\
\hline MINLP & $\begin{array}{l}\text { Mixed integer-non linear } \\
\text { programming }\end{array}$ & $\begin{array}{l}\text { el } \\
\text { eng }\end{array}$ & $\begin{array}{l}\text { Electric } \\
\text { Engine }\end{array}$ \\
\hline MARPOL & $\begin{array}{l}\text { International Convention for } \\
\text { the Prevention of Pollution } \\
\text { from Ships }\end{array}$ & $\begin{array}{l}\text { eq } \\
\text { mech } \\
\text { neq }\end{array}$ & $\begin{array}{l}\text { Equality (constraint) } \\
\text { Mechanical } \\
\text { Inequality (constraint) }\end{array}$ \\
\hline $\mathrm{ME}$ & Main engine & prop & Propulsion \\
\hline MCR & $\begin{array}{l}\text { Maximum continuous rating } \\
{[\mathrm{kW}]}\end{array}$ & th & Thermal \\
\hline NPV & Net present value [USD] & & \\
\hline OM & Operational mode & & \\
\hline $\mathrm{SCR}$ & Selective catalytic reactor & & \\
\hline SG & Shaft generator & & \\
\hline SM & Shaft motor & & \\
\hline USD & US dollar & & \\
\hline WHR & Waste heat recovery & & \\
\hline \multicolumn{4}{|c|}{ Roman symbols } \\
\hline$b$ & Constraint vector & & \\
\hline$c_{p}$ & Specific heat $[\mathrm{J} / \mathrm{kgK}]$ & & \\
\hline$f$ & Objective function & & \\
\hline$f_{\text {corr }}$ & $\begin{array}{l}\text { Correction function for off- } \\
\text { design operations }\end{array}$ & & \\
\hline$g(x)$ & Constraint function & & \\
\hline$n_{i, o n}$ & $\begin{array}{l}\text { Number of components in the } \\
\text { i-th group running }\end{array}$ & & \\
\hline$N_{c y l}$ & Number of cylinders & & \\
\hline$\dot{m}$ & Mass flow rate $[\mathrm{kg} / \mathrm{s}]$ & & \\
\hline$p$ & Pressure $[\mathrm{Pa}]$ & & \\
\hline$P$ & Power $[\mathrm{kW}]$ & & \\
\hline$P_{n}(x)$ & $x$-th degree polynome & & \\
\hline$\dot{Q}$ & Heat flow $[\mathrm{kW}]$ & & \\
\hline V & Volume $\left[\mathrm{m}^{3}\right]$ & & \\
\hline \multicolumn{4}{|c|}{ Greek symbols } \\
\hline$\eta$ & Efficiency & & \\
\hline$\eta_{\text {mech,TC }}$ & $\begin{array}{l}\text { Turbocharger mechanical } \\
\text { efficiency }\end{array}$ & & \\
\hline$\eta_{\text {vol }}$ & Engine volumetric efficiency & & \\
\hline$\lambda$ & Component load & & \\
\hline$\lambda_{x x \rightarrow y y}$ & $\begin{array}{l}\text { Load of component } x x \text { related } \\
\text { to the fulfilment of the } \\
\text { demand } y y\end{array}$ & & \\
\hline
\end{tabular}

